\title{
Power Transfer Potential to the Southeast in Response to a Renewable Portfolio Standard: Interim Report 2
}

May 2009

Prepared by

Stanton W. Hadley - ORNL

Thomas Key - EPRI

Rajat Deb - LCG Consulting 


\title{
DOCUMENT AVAILABILITY
}

Reports produced after January 1, 1996, are generally available free via the U.S. Department of Energy (DOE) Information Bridge:

Web site: http://www.osti.gov/bridge

Reports produced before January 1, 1996, may be purchased by members of the public from the following source:

\author{
National Technical Information Service \\ 5285 Port Royal Road \\ Springfield, VA 22161 \\ Telephone: 703-605-6000 (1-800-553-6847) \\ TDD: 703-487-4639 \\ Fax: 703-605-6900 \\ E-mail: info@ntis.fedworld.gov \\ Web site: http://www.ntis.gov/support/ordernowabout.htm
}

Reports are available to DOE employees, DOE contractors, Energy Technology Data Exchange (ETDE) representatives, and International Nuclear Information System (INIS) representatives from the following source:

Office of Scientific and Technical Information

P.O. Box 62

Oak Ridge, TN 37831

Telephone: 865-576-8401

Fax: 865-576-5728

E-mail: reports@adonis.osti.gov

Web site: http://www.osti.gov/contact.html

\begin{abstract}
This report was prepared as an account of work sponsored by an agency of the United States Government. Neither the United States government nor any agency thereof, nor any of their employees, makes any warranty, express or implied, or assumes any legal liability or responsibility for the accuracy, completeness, or usefulness of any information, apparatus, product, or process disclosed, or represents that its use would not infringe privately owned rights. Reference herein to any specific commercial product, process, or service by trade name, trademark, manufacturer, or otherwise, does not necessarily constitute or imply its endorsement, recommendation, or favoring by the United States Government or any agency thereof. The views and opinions of authors expressed herein do not necessarily state or reflect those of the United States Government or any agency thereof.
\end{abstract}




\title{
Power Transfer Potential to the Southeast in Response to a Renewable Portfolio Standard: Interim Report 2
}

\author{
Stanton W. Hadley - ORNL \\ Thomas Key - EPRI \\ Rajat Deb - LCG Consulting
}

May 2009

OAK RIDGE NATIONAL LABORATORY

Oak Ridge, Tennessee 37831 managed by

UT-BATTELLE, LLC

for the

U.S. DEPARTMENT OF ENERGY

under contract No. DE-AC05-00OR22725 



\section{CONTENTS}

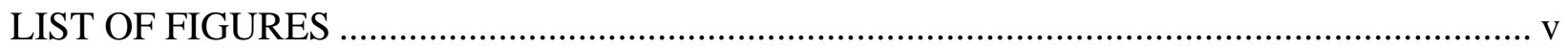

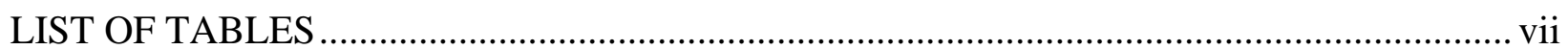

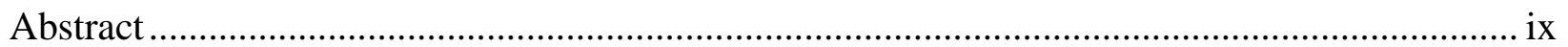

1. Introduction - SE needed renewables under RPS................................................... 1

2. Available renewable resources in the Southeast ......................................................... 3

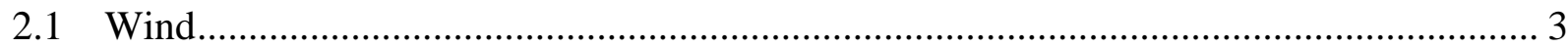

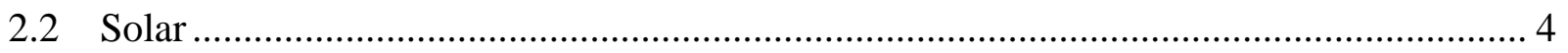

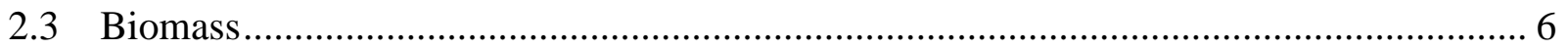

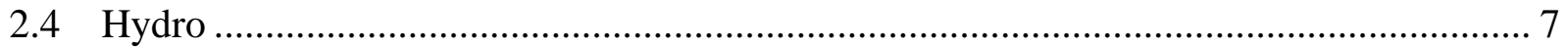

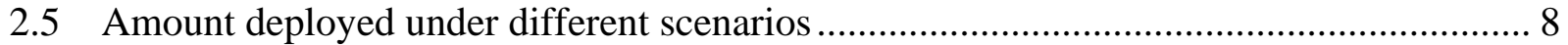

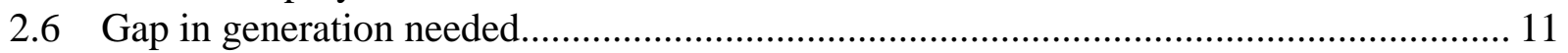

3. Planned transmission resources in Southeast.............................................................. 13

3.1 Introduction (UPLAN model) ...................................................................... 13

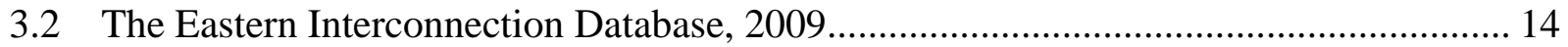

4. Alternative means to meet RPS goal in SE ................................................................ 23

4.1 RPS expectation with regional balancing of supply/demand ................................. 23

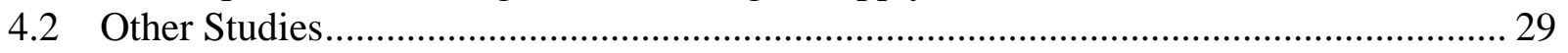

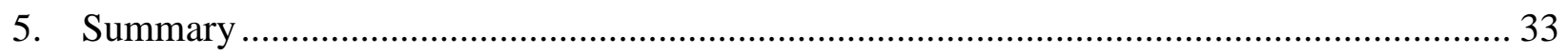

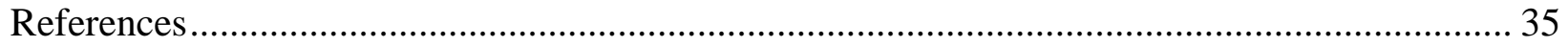

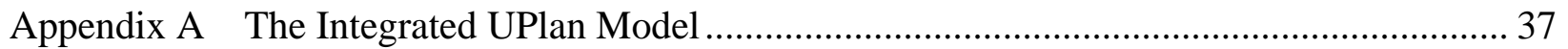





\section{LIST OF FIGURES}

Figure 1. Thirteen NERC Regions used in NEMS, NESSIE, and UPLAN Models. 2

Figure 2. Locations of Southeast Offshore Wind in EWITS study 4

Figure 3. Price difference between solar PV levelized costs and residential electricity in 2015 with a 13\% increase in residential prices and no incentives (Paidipati et al. 2008) 5

Figure 4. Total potential biomass resources in the southeast by type (Milbrandt 2005) 6

Figure 5. Location of Hydroelectric facilities in the Southeast (EPA 2008) 7

Figure 6. SERC Generation Development (Source: SERC Reliability Corporation Information Summary, July 2008) 14

Figure 7. Normal Base Electricity Transfer and First Contingency Incremental Transfer Capabilities (Source: NERC 2004 Summer Assessment) 15

Figure 8. SERC Inter- and Intra-Regional Interconnections 16

Figure 9. 2009 Peak Demand (MW) by Region 17

Figure 10. Breakdown of Capacity by Fuel Type in Eastern Interconnect (2009) 17

Figure 11. Breakdown of Capacity by ISO/Regions Eastern Interconnect (2009) 18

Figure 12. 2020 Peak Demand (MW) by Region 20

Figure 13. Total Capacity by Region (2020) 20

Figure 14. Total Capacity by Fuel Type in the studied Eastern Interconnection (2020) 21

Figure 15. Wind Resources Relative to Population Centers. 23

Figure 16. Renewable Share of Total Generation for Three Scenarios 24

Figure 17. US Annual Electricity Generation under Different Scenarios (TWh) 25

Figure 18. Regional Variation in Renewable Generation, RPS Policy Case (2020) 26

Figure 19. Regional Electricity Generation, RPS Policy Case 2020

Figure 20. SPP Generation with no policy or federal RPS or federal climate policy 27

Figure 21 SERC Generation with no policy or federal RPS or federal climate policy 28

Figure 22. Comparison of Regional Cost of Electricity, $\mathrm{CO}_{2}$ Policy Case 28

Figure 23 ECAR Generation with no policy or federal RPS or federal climate policy 29

Figure 24. 20\% Wind Energy Scenario Conceptual Transmission Overlay (Source JCSP 2008)30

Figure 25. Scenario 2 Interface Contour: Annual Energy Difference Copper Sheet Minus Constrained Case (Source NREL 2009) 



\section{LIST OF TABLES}

Table 1. 2020 Southeast electricity loads (TWh) 2

Table 2. Potential Onshore Wind Capacity in SERC region by state (EPRI) 3

Table 3. Southeast states' cumulative rooftop PV capacity (MW) in 2015 under BAU and best case scenarios (Paidipati et al. 2008) 5

Table 4. Estimated National Waterpower Capacity Gains (MW) by 2025 (Source EPRI 2007) 8

Table 5. Southeast 2020 electricity capacity, generation and load from AEO2009 post-stimulus (EIA 2009) 9

Table 6. Southeast electricity capacity, generation and load from EIA evaluation of RPS policy in American Clean Energy and Security Act (Source EIA2009b)

Table 7. Southeastern renewable generation in 2030 under Markey Bill (TWh) (Source Sullivan 2009)

Table 8. Renewable resources in 2030 from different scenarios and models

Table 9. Southeast RPS Requirement and Potential Supplies (2020)

Table 10. Summary of Resources and Loads in Eastern Interconnect (2009)

Table 11. Transmission Expansion as per Interconnection agreements (2020)

Table 12. Summary of Resources and Loads in Eastern Interconnect (2020)

Table 13. Annual Zonal Flows for SERC

Table 14. Annual Regional Wind Generation (2020)

Table 15. Three Possible Policy Scenarios, Source EPRI Report 1015805, March 2009 "Role of

Future Generation Options for the U.S. Electric Sector" 



\begin{abstract}
Electricity consumption in the Southeastern US, not including Florida, is approximately $24 \%$ of the total US. The availability of renewable resources for electricity production is relatively small compared to the high consumption. Therefore meeting a national renewable portfolio standard (RPS) is particularly challenging in this region. Neighboring regions, particularly to the west, have significant wind resources and given sufficient long distant transmission these resources could serve energy markets in the SE. This report looks at renewable resource supply relative to demands and the potential for power transfer into the SE. It shows that development of wind resources will depend not only on available transmission capacity but also on electricity supply and demand factors.
\end{abstract}





\section{Introduction - SE needed renewables under RPS}

Current discussions about increasing the amount of renewable energy in the U.S. center on the creation of a Renewable Portfolio Standard (RPS). Each utility would be required to provide an increasing fraction of their total production from qualified renewable resources. A key concern is that the Southeastern U.S. does not have as many cost-effective resources available. Utilities there may need to import significant quantities of renewable energy from other regions of the country, most likely wind power from the Midwestern states. Other options may be available too, such higher-cost local generation, purchase of renewable energy credits without the physical transmission of power, or payment of an alternative compliance payment to the U.S. Treasury.

Under the recently proposed RPS from Sen. Bingaman, "each utility that sells electricity to electric consumers shall obtain a percentage of the base quantity of electricity the electric utility sells to electric consumers in any calendar year from new renewable energy, existing renewable energy, or energy efficiency." The percentage ramps up from 4\% in 2011 to 20\% by 2021 and thereafter. The utility will utilize renewable energy credits, energy efficiency credits (not more than $25 \%$ of total) and/or payments of $3 \notin / \mathrm{kWh}$ (adjusted for inflation). Tradeable credits will be issued to new renewable production, but existing renewable energy will receive non-tradable credits. Existing hydroelectric power and municipal solid waste facilities are not included in either the numerator or denominator when calculating the percentage of generation from renewable power.

Other bills have been proposed and any final law will likely be different from all of the current proposals. For example, the Waxman-Markey bill sets the standard at $17.5 \%$ in 2020, with a long-term goal of $25 \%$ from 2025 to 2039 . As a consequence of these variations, this paper will evaluate the potential impact on the Southeast of a 15\% RPS by 2020; any higher amount will simply amplify the impacts. We will also show some results from a 20\% RPS in order to show the differential involved with higher RPS targets. A recent study from NREL compares the requirements and effects of three recently proposed bills: the Bingaman, Markey, and WaxmanMarkey (Sullivan, et al. 2009).

The regions used for this analysis (Figure 1) are those defined in the Energy Information Administration (EIA) NEMS model (DOE 2008). These regions are based on the North American Electric Reliability Council (NERC) regions from 2004 and have not been adjusted yet to reflect several changes in regional boundaries, most notably the addition of Gateway (eastern Missouri and southern Illinois) and most of Kentucky to SERC. For consistency with the EIA data and reporting, the models used in this study, EPRI NESSIE model and LCG's UPLAN model, also use these regions in their analysis of the electric power sector. 


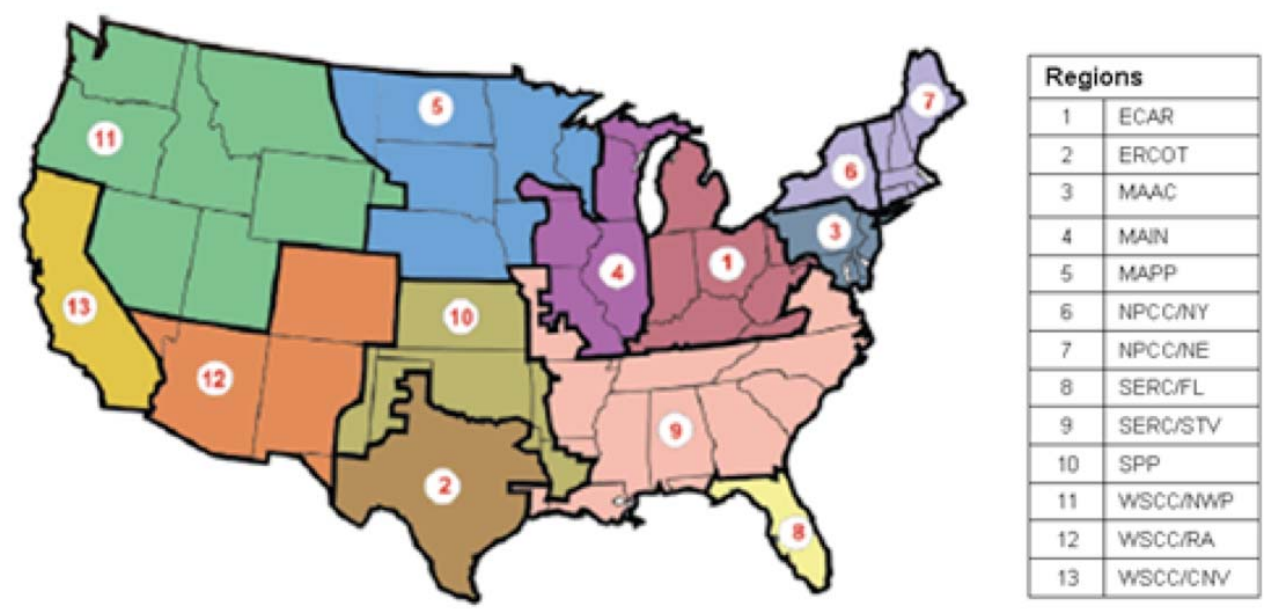

Figure 1. Thirteen NERC Regions used in NEMS, NESSIE, and UPLAN Models.

Using the demands from the latest EIA Annual Energy Outlook 2009 Reference Case (postStimulus Bill), the expected sales of electric power (Net Energy for Load) in the Southeast (SERC and FRCC) are shown in Table 1. With a 15\% RPS, 186 TWh would need to be produced or delivered to the Southeast while a 20\% RPS would require $248 \mathrm{TWh}$ in 2020. Because of the variety of definitions of "renewable" the actual amount needed may be different. For example, the Bingaman bill does not include existing hydropower and municipal solid waste. When excluding these sources, the total amount of renewables needed in the 15\% RPS drops from 186 TWh to $180 \mathrm{TWh}$. However, since these two technologies provide $39 \mathrm{TWh}$ in 2020 (in the AEO2009 Reference scenario) the amount of other renewables required is higher than if they are included. See this project's Task 1 interim report (Hadley and Key 2009) for more details.

Table 1. 2020 Southeast electricity loads (TWh)

\begin{tabular}{cccc}
\hline & SERC & FRCC & Total SE \\
\hline Net Energy for Load & 970 & 270 & 1240 \\
$15 \%$ of NEL & 145 & 40 & 186 \\
$20 \%$ of NEL & 194 & 54 & 248 \\
\hline
\end{tabular}




\section{Available renewable resources in the Southeast}

The Southeast has a number of renewable resources that can be used to meet a RPS. However, the total amount economically available is likely less than $15 \%$ of total generation. Several studies have been done that look at renewable energy resources in all or part of the southeast. The key studies used for the amounts described below are:

- Annual Energy Outlook 2009 by the Energy Information Administration, March 2009

- Energy Market and Economic Impacts of S. 2191, the Lieberman-Warner Climate Security Act of 2007 by EIA, March 2008

- Yes We Can: Southern Solutions for a National Renewable Energy Standard, Southern Alliance for Clean Energy Feb. 2009

- EPRI analysis of Wind capacities Feb. 2009 (?)

- A Geographic Perspective on the Current Biomass Resource Availability in the United States, NREL/TP-560-39181, National Renewable Energy Laboratory, December 2005.

- Rooftop Photovoltaics Market Penetration Scenarios, NREL/SR-581-42306, NREL, Feb. 2008.

- Florida Renewable Energy Potential Assessment, Navigant Consulting, Dec. 2008.

- Eastern Interconnection Wind Integration \& Transmission Study (Draft), NREL, Midwest ISO, and Enernex, 2009.

A separate study is underway at ORNL funded by the Energy Foundation that will conduct a more thorough literature review of the amounts of each renewable energy category that is potentially available in the SE.

\subsection{Wind}

Onshore wind capabilities in the Southeast are relatively modest. Less than 20 TWh of power could potentially be generated in the SE states (Table 2) using data from EPRI. The table shows the amounts if capacity factors for wind turbines vary between $18 \%$ and $37 \%$ depending on the class of wind. The wind resource estimates for in states that have some territory in other reliability regions have been downscaled to reflect the amounts within the SERC and FRCC borders. Note that half of the potential production in SERC comes from Missouri, with its northwestern portion having the best quality of wind potential. This region is still rather distant from the rest of the SERC region and load centers.

Table 2. Potential Onshore Wind Capacity in SERC region by state (EPRI)

\begin{tabular}{lcccccccccccc}
\hline & AL & AR & FL & GA & LA & MO & MS & NC & SC & TN & VA & Total \\
\hline Potential Capacity (GW) & 0 & 0.3 & 0 & 0 & 0 & 6.0 & 0 & 1.9 & 0.3 & 1.1 & 1.8 & 11.4 \\
Expected prod. (TWh) & 0.0 & 0.5 & 0.0 & 0.0 & 0.0 & 9.6 & 0.0 & 3.5 & 0.5 & 2.1 & 3.3 & 19 \\
\hline
\end{tabular}

Additionally, offshore wind capacity is potentially available. However, this form of wind energy has not yet been tapped within the US. It is beginning to be developed in Northern Europe, in the North Sea and in the Atlantic off the coast of Ireland and England. The EWITS study developed estimates of wind capacity along the Atlantic coast. These were largely along the Virginia and North Carolina coasts, as shown in Figure 2. The total amount in the SERC region was 4,000 
MW, even in the aggressive penetration scenario. At a capacity factor of $40 \%$, this totals to 14 TWh per year.

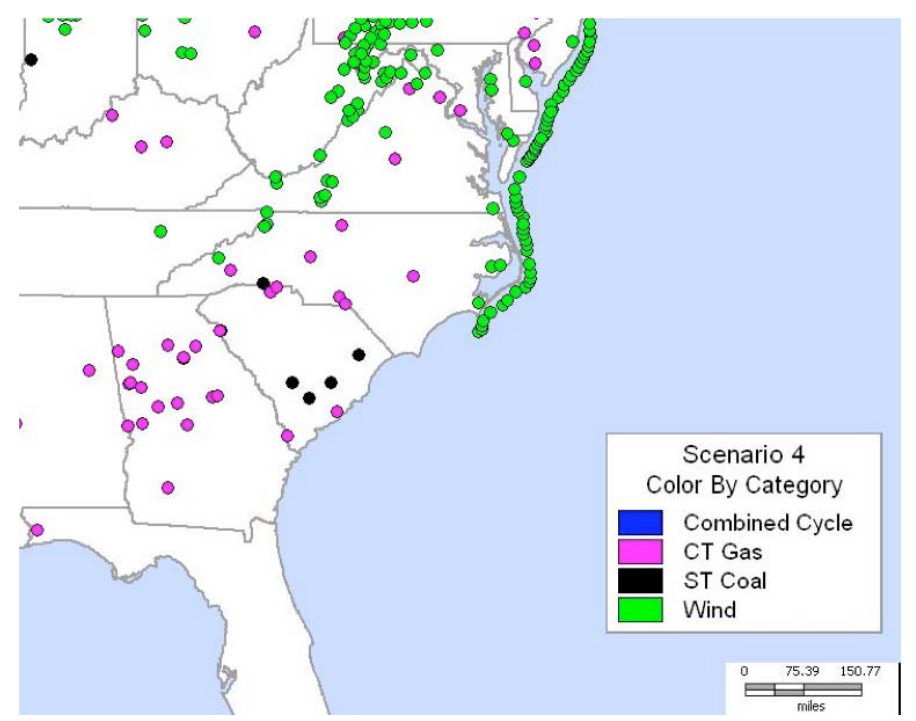

Figure 2. Locations of Southeast Offshore Wind in EWITS study

Combined, the total amount of potential wind capacity for the southeast is roughly $15 \mathrm{GW}$, with a production amount of $33 \mathrm{TWh}$. This includes a speculative $4 \mathrm{GW}$ of offshore wind plus $6 \mathrm{GW}$ in upstate Missouri.

Separately, Navigant Consulting performed an analysis of renewable energy potential in the state of Florida (Navigant 2008). Their analysis projected $67 \mathrm{MW}$ of onshore wind and $105 \mathrm{MW}$ of offshore wind by 2020 in the most favorable circumstances. These contribute $0.5 \mathrm{TWh}$ of generation to the region.

\subsection{Solar}

Solar capacity could be extensive in the southeast, depending on the cost of deployment. One study of rooftop PV potential from NREL shows much of Florida (and small parts of the rest of the Southeast) with solar prices below residential electricity prices in 2015 (Figure 3) (Paidipati et al. 2008). The technical potential (regardless of cost) is on the order of $200 \mathrm{GW}$, but actual deployment will be much smaller. 


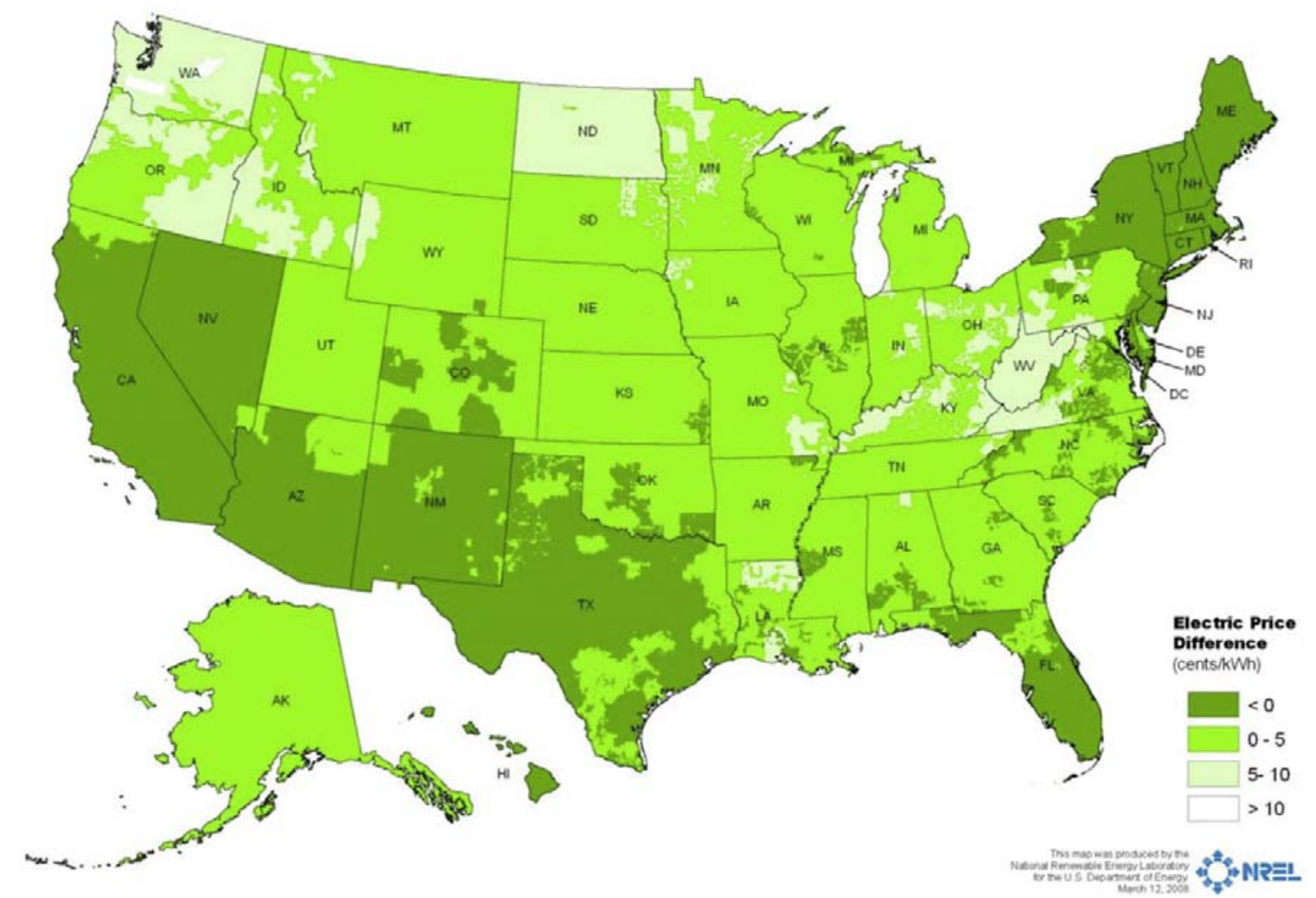

Figure 3. Price difference between solar PV levelized costs and residential electricity in 2015 with a $13 \%$ increase in residential prices and no incentives (Paidipati et al. 2008)

The authors of the study made state-by-state analyses of existing policies and the effect of potential changes to policies. Under their Business as Usual scenario, they projected cumulative installations of rooftop PV for the southeast at $213 \mathrm{MW}$. Under their best-case assumptions, they forecasted almost $1,000 \mathrm{MW}$ (Table 3 ). Assuming a $25 \%$ capacity factor, this works out to around $2 \mathrm{TWh}$, much less than the required $186 \mathrm{TWh}$ identified in Table 1. In their analysis, they proposed various policies to encourage further solar development, most of which North Carolina already has planned (note that the amount is the same for both the BAU and best case scenarios.)

Table 3. Southeast states' cumulative rooftop PV capacity (MW) in 2015 under BAU and best case scenarios (Paidipati et al. 2008)

\begin{tabular}{lrr}
\hline State & Business as Usual & Best Case \\
\hline Alabama & 1 & 87 \\
Arkansas & 1 & 1 \\
Florida & 30 & 330 \\
Georgia & 11 & 41 \\
Louisiana & 1 & 34 \\
Mississippi & 2 & 92 \\
North Carolina & 154 & 154 \\
South Carolina & 3 & 43 \\
Tennessee & 6 & 84 \\
Virginia & 3 & 62 \\
West Virginia & 1 & 8 \\
\cline { 2 - 3 }$\quad$ Total & 213 & 936 \\
\hline \multicolumn{2}{r}{}
\end{tabular}


A separate study by Navigant of the potential for renewable energy in Florida included an analysis of the potential for ground-mounted PV in the state. They projected a technical potential of $37 \mathrm{GW}$ in 2020, representing 600 square miles or $\sim 1 \%$ of the state's area. Depending on the renewable energy policies (including renewable energy credits) they projected between 0 and 9.5 GW of ground-mounted PV by 2020 (producing up to 21.6 TWh), roughly one fourth of the technical potential. The Southern Alliance for Clean Energy extrapolated these results to the eleven states of the southeast and came up with a total technical potential of $346 \mathrm{GW}$ and feasible capacity of $74 \mathrm{GW}$. The feasible generation was $160 \mathrm{TWh}$, assuming favorable renewable energy policies and RECs. With the higher price differential for solar in the rest of the southeast (Figure 3) it is less likely that this solar amount could be feasible by 2020 .

\subsection{Biomass}

Biomass generation may be the largest supply of renewable production in the southeast. According to the NREL report A Geographic Perspective on the Current Biomass Resource Availability in the United States (Milbrandt 2005) the total potential biomass resources available in the southeast is around 120 million metric tonnes per year. Assuming $16 \mathrm{mmbtu} /$ tonne and a heat rate of $10,000 \mathrm{btu} / \mathrm{kWh}(34 \%$ efficiency) the total potential electricity from these resources is $145 \mathrm{TWh}$, a significant fraction of the required $186 \mathrm{TWh}$ identified in Table 1. With a capacity factor of $70 \%$, this translates into a total potential electric capacity of around $24 \mathrm{GW}$. However, even if this total potential were utilized, some portion of it would be used for liquid biofuels rather than electricity production. As such, it would not qualify for the renewable portfolio standard, which only applies to electricity production. Figure 4 shows the split of resources by type of fuel.

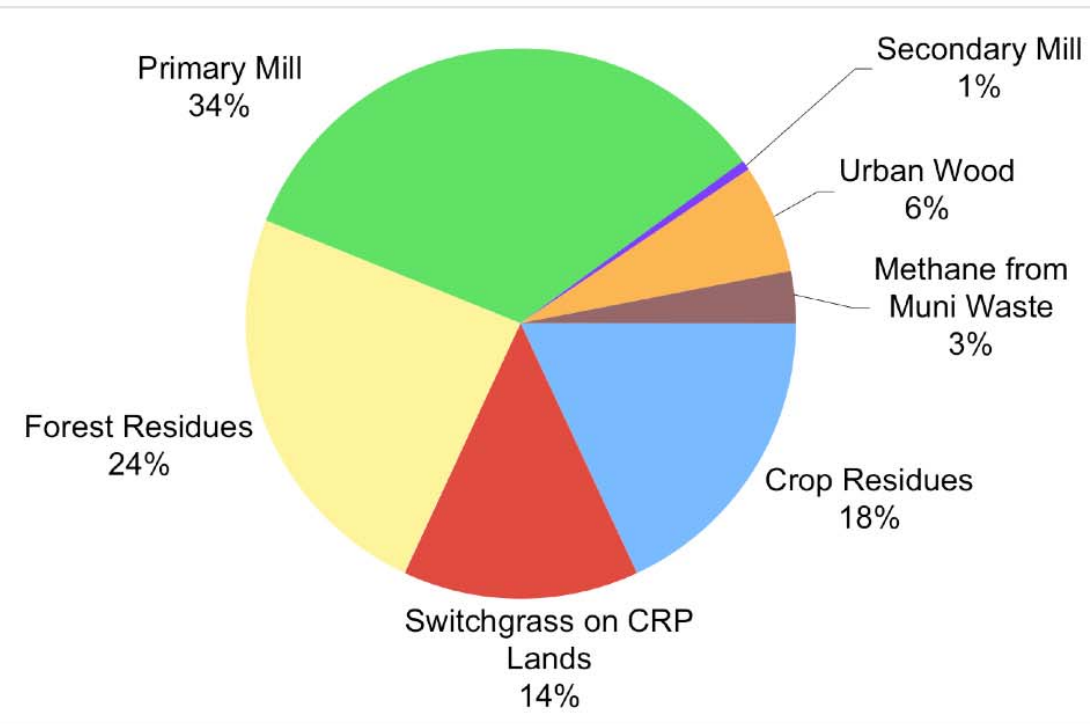

Figure 4. Total potential biomass resources in the southeast by type (Milbrandt 2005)

The AEO2009 projects 12 TWh of wood and other biomass production in 2020 in the southeast. Much of this generation is from cofiring in a coal-fired power plant, rather than as dedicated biomass capacity. In addition, it lists another 3 TWh from biogenic municipal waste, but this 
does not qualify for the RPS according to Bingaman's proposed bill. The analysis by EIA of Senate bill 2191 (the Lieberman-Warner Climate Security Act) placed biomass generation in the southeast at 55 TWh by 2020, while an analysis of the RPS within the American Clean Energy and Security Act of 2009 reported 34 TWh of production.

\subsection{Hydro}

Hydroelectricity is currently the most widely used renewable resource within the southeast. The resources have been developed by the TVA, the US Army Corps of Engineers, and other utilities mainly in the central part of the southeast (Figure 5). Total resources in the SERC and FRCC region are between $12 \mathrm{GW}$ and $13 \mathrm{GW}$ with a typical production of $35 \mathrm{TWh}$. (Wet and dry years, such as the drought in 2006 and 2007, will cause hydropower output to vary by as much as $50 \%$.) Most major resources have been developed although some additional incremental generation may be realized by upgrading existing hydro turbines and improving operating efficiency at existing facilities. Nameplate capacity in SERC rose from 12.3 GW in 2004 to $12.7 \mathrm{GW}$ in 2007.

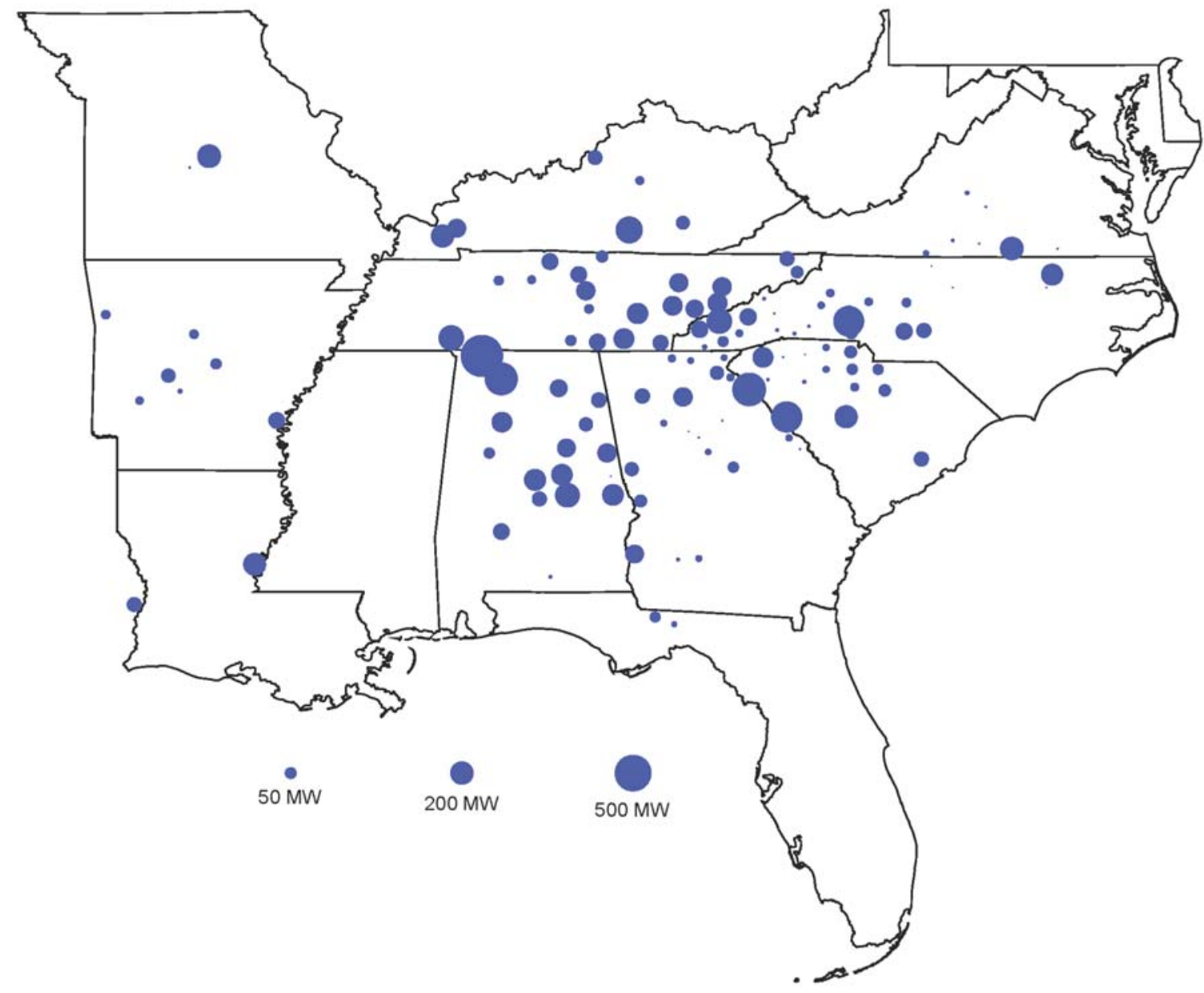

Figure 5. Location of Hydroelectric facilities in the Southeast (EPA 2008)

In many RPS proposals, including the Bingaman proposal described above, existing hydropower does not count towards meeting the standard, but is also removed from the total generation to which the percentage is applied. 
Another new technology with potential is hydrokinetic machines that operate in free-flowing rivers or ocean currents. Tidal and wave power equipment are also under research. However, these technologies are currently only at the developmental or pilot-scale level and are unlikely to provide a significant portion of the needs under an RPS.

EPRI has identified a nationwide potential for hydro capacity gains of $3.7 \mathrm{GW}$ by 2015 and 23 GW by 2025, with a total potential of $85-95$ GW (EPRI 2007). However, they provide no geographic breakdown of this amount. Some $10 \mathrm{GW}$ of this potential is at existing facilities or small hydro and so may be applicable to southeastern rivers and dams (Table 4). Between this new capacity and increased efficiency at existing dams, they project a potential nationwide generation of 40-50 TWh from conventional hydro. The southeast would only capture a fraction of that. Hydrokinetic capabilities are largely from tidal in-stream operations, which are not being pursued currently in the southeast but rather in the Pacific Northwest, Hawaii, and New York.

Table 4. Estimated National Waterpower Capacity Gains (MW) by 2025 (Source EPRI 2007)

\begin{tabular}{|c|c|c|c|c|c|}
\hline Waterpower Technology & 2006 & Potential & By 2010 & By 2015 & By 2025 \\
\hline \multicolumn{6}{|l|}{ Conventional hydropower } \\
\hline Large Hydro (>30 MW) & 66,536 & & 0 & 0 & 0 \\
\hline $\begin{array}{l}\text { Capacity gains at existing large } \\
\text { and small hydro }\end{array}$ & $\sim 100$ & 4,300 & 375 & 1,000 & 2,300 \\
\hline New small hydro $(>1 \mathrm{MW}<30)$ & 8,023 & 36,000 & 25 & 500 & 2,000 \\
\hline New low power hydro $<1 \mathrm{MW}$ & 313 & 22,000 & 100 & 350 & 700 \\
\hline New hydro at existing dams & - & & 25 & 500 & 5,000 \\
\hline Conventional hydro potential realized & & & 525 & 2,350 & 10,000 \\
\hline \multicolumn{6}{|l|}{ Hydrokinetic } \\
\hline Tidal instream & Demos & 300 & 115 & 300 & 3,000 \\
\hline $\begin{array}{l}\text { Instream and constructed } \\
\text { waterways }\end{array}$ & - & 12,500 & 0 & 30 & ? \\
\hline Hydrokinetic potential realized & & & 115 & 330 & 3,000 \\
\hline Ocean energy (wave) & Demos & $10,000-20,000$ & 84 & 1,000 & 10,000 \\
\hline TOTAL & 74,972 & $85,100-95,100$ & 724 & 3,680 & 23,000 \\
\hline
\end{tabular}

\subsection{Amount deployed under different scenarios}

Under the newest Annual Energy Outlook 2009 Reference scenario (released in April and including the impact of the recent stimulus funds), only $18 \mathrm{GW}$ of renewables are used in the southeast, generating 68 TWh (Table 5). Of this amount, only 29 TWh of generation is from qualified renewables; the remainder is from hydroelectric and municipal waste. It does include 3.6 GW of wind (3.57 GW in Florida onshore and the $30 \mathrm{MW}$ existing in Tennessee). The biomass generation amount of $19 \mathrm{TWh}$ includes both dedicated biomass plants $(1.4 \mathrm{GW})$ plus cofiring in some of the region's coal-fired plants. 
Table 5. Southeast 2020 electricity capacity, generation and load from AEO2009 poststimulus (EIA 2009)

\begin{tabular}{lrr}
\hline & $\begin{array}{c}\text { Capacity } \\
(\text { GW })\end{array}$ & $\begin{array}{c}\text { Generation } \\
(\text { TWh })\end{array}$ \\
\hline Coal & 149.7 & 572 \\
Oil \& Gas & 232.5 & 188 \\
Nuclear & 38.7 & 334 \\
Pumped Storage/Other & 7.7 & -1 \\
Conventional Hydropower & 12.2 & 35 \\
Geothermal & 0.0 & 0 \\
Biogenic Municipal Waste & 0.8 & 4 \\
Wood and Other Biomass & 1.4 & 19 \\
Solar Thermal & 0.0 & 0 \\
Solar Photovoltaic & 0.0 & 0 \\
Wind & 3.6 & 11 \\
Offshore Wind & 0.0 & 0 \\
less gen for own use & & -10 \\
Electric Gen for Customers & 285.4 & 1152 \\
Net imports from other regions & & 77 \\
Purchase from CHP & & 1240 \\
Net Energy for Load & & \\
\hline
\end{tabular}

The amounts in this scenario expand the amount of renewables when compared to earlier reference cases due to the policies in the American Reinvestment and Recovery Act. Other recent NEMS scenarios by EIA had even more development. The analysis by EIA of the renewable energy standard within the proposed American Clean Energy and Security Act of 2009 (EIA 2009) placed qualified renewable generation in the southeast at 44 TWh by 2020 (Table 6). Biomass production increased from $19 \mathrm{TWh}$ to $34 \mathrm{TWh}$; other renewables essentially stayed the same. Even this scenario has only a fourth of what is needed for the region to supply its own share of a $15 \%$ RPS requirement. 
Table 6. Southeast electricity capacity, generation and load from EIA evaluation of RPS policy in American Clean Energy and Security Act (Source EIA2009b)

\begin{tabular}{lrr}
\hline Coal & $\begin{array}{c}\text { Capacity } \\
(\text { GW })\end{array}$ & $\begin{array}{c}\text { Generation } \\
(\text { TWh })\end{array}$ \\
Oil \& Gas & 148.9 & 558 \\
Nuclear & 230.2 & 184 \\
Pumped Storage/Other & 38.7 & 334 \\
Conventional Hydropower & 7.7 & -1 \\
Geothermal & 12.2 & 35 \\
Biogenic Municipal Waste & 0.0 & 0 \\
Wood and Other Biomass & 0.8 & 4 \\
Solar Thermal & 1.6 & 34 \\
Solar Photovoltaic & 0.0 & 0 \\
Wind & 0.0 & 0 \\
Offshore Wind & 3.6 & 11 \\
less gen for own use & 0.0 & 0 \\
Electric Gen for Customers & & -10 \\
Net imports from other regions & 284.1 & 1149 \\
Purchase from CHP & & 79 \\
Net Energy for Load & & 1240 \\
\hline
\end{tabular}

A recently released study by NREL on RPS proposals (Sullivan 2009) includes a table that shows the state-by-state generation by different renewable technologies (Table 7). The analysis was done using their REeDS model and the data shown in the table is the sum for the eleven states in the southeast (as opposed to the SERC and FRCC regions). The data represents their modeling of the Markey's bill H.R. 890, the American Renewable Energy Act for the year 2030. Even though this bill required the most renewable generation of the three studied, $25 \%$ by 2025 , the southeast states did not generate the required amounts. Instead, they were expected to import renewable power and/or purchase renewable energy credits from states with surpluses.

Table 7. Southeastern renewable generation in 2030 under Markey Bill (TWh) (Source Sullivan 2009)

\begin{tabular}{lrrrr}
\hline & Wind & Solar & \multicolumn{1}{c}{ Bio } & Total \\
\hline Alabama & 0 & 0 & 1.4 & 1.4 \\
Arkansas & 0.4 & 0 & 0.7 & 1.1 \\
Florida & 2.9 & 3.2 & 11 & 17.1 \\
Georgia & 2.1 & 0 & 1.6 & 3.7 \\
Louisiana & 3.9 & 2.8 & 0.7 & 7.4 \\
Mississippi & 0 & 0 & 1.2 & 1.2 \\
Missouri & 13.4 & 0 & 0.8 & 14.2 \\
North Carolina & 10.8 & 7.0 & 7.0 & 24.8 \\
South Carolina & 0.4 & 1.5 & 2.2 & 4.1 \\
Tennessee & 1.0 & 0 & 1.5 & 2.5 \\
Virginia & 2.5 & 1.7 & 1.4 & 5.6 \\
Total & 37.4 & 16.2 & 29.5 & 83.1 \\
\hline
\end{tabular}


The amounts above represent only the electricity generated by the electricity sector and does not include industrial or other sectors' generation for their own end-use. Particularly in the southeast, generation from biomass through cogeneration at paper mills provide significant quantities of electricity. These are not greatly affected by changes in plans and do not qualify for tradable renewable energy credits in some of the bills under discussion. Under the AEO2009 with stimulus package scenario by 2030 there is 37 TWh of qualified renewable resources from endusers while in the Waxman RPS the total is only 36 TWh (Table 8).

Table 8. Renewable resources in 2030 from different scenarios and models

\begin{tabular}{l|r|r|r|r|r|r|r}
\hline & Markey RPS & \multicolumn{3}{|c|}{ AEO2009 with Stimulus (NEMS) } & \multicolumn{3}{c}{ Waxman RPS (NEMS) } \\
& (REeDS) & Elec Sector & EndUse & Total & Elec Sector & EndUse & \multicolumn{1}{c}{ Total } \\
\hline Wind & 37 & 11 & 0 & 11 & 11 & 0 & 11 \\
Solar & 16 & 0 & 5 & 5 & 0 & 7 & 7 \\
Biomass & 30 & 18 & 32 & 50 & 129 & 28 & 157 \\
Total & 83 & 29 & 37 & 66 & 139 & 36 & 175 \\
\hline
\end{tabular}

Another point to be made from this table is that different models and associated assumptions can give large differences in the amount and type of generation developed. The REeDS model analysis of the Markey RPS develops a large amount of solar and wind resources while the NEMS analysis supply most renewable generation in the southeast from biomass.

\subsection{Gap in generation needed}

So how much of a gap is there between what is needed to satisfy an RPS of $15 \%$ and the possible sources within the southeast? Table 9 lists the amounts of supplies potentially available within the region, based on the statements from sources listed above. None of the sources by themselves can meet the requirements. Solar comes closest, but these values are based on a very rough extrapolation of technical potential for the region based on the Florida study. It does not take into account the time it would take to construct such sources, nor does it consider the cost to provide that level of demand. Biomass has the next largest potential, but again, the amount is based on the maximum utilization of all resources without regard to construction time or economic cost. It also does not consider that some of the biomass available will be used for liquid fuels. 
Table 9. Southeast RPS Requirement and Potential Supplies (2020)

\begin{tabular}{ll}
\hline Generation Needed in $\mathbf{2 0 2 0}$ & $\mathbf{1 8 6}-\mathbf{2 4 8}$ TWh (15\% to 20\% RPS) \\
\hline Wind Resources & 19 TWh generated within SERC (EPRI) \\
& 6.7 TWh Onshore + 14 TWh Offshore (EWITS) \\
& $7-11$ TWh (EIA) \\
& 2 TWh generation by 2015 Rooftop potential (NREL) \\
& $0-160$ TWh ground-mount potential depending on policies \\
Solar & (SACE and Navigant) \\
& 145 TWh technical potential biomass generation (Calculated \\
& from NREL supply estimates) \\
& $19-55$ TWh generated in 2020 depending on policies (EIA) \\
Biomass & 46 TWh generated by 2020 in SERC with CO 2 policy (EPRI) \\
& $40-50$ TWh generation nationally (SERC amount \\
& unknown) (EPRI) \\
Few Hydro (incremental) & From $\mathbf{1 7 4}$ TWh needed to less than zero depending on \\
solar and biomass deployment
\end{tabular}

When considering how much wind from other regions will be needed to meet the renewable portfolio standard in the southeast, it becomes clear that without massive investment in biomass and solar technologies, imported wind is the best choice. To bring in this wind large amounts of transmission will be needed. It then becomes a question of how much the solar and biomass can realistically be deployed in the next 11 years. While biomass generation has an established base in the region, a scale-up from the current projection of $12 \mathrm{TWh}$ will require the construction of new plants, conversion of many existing fossil plants, and an established biomass fuel production infrastructure. Solar production has not been developed in the southeast yet, so expansion to cover $\sim 1 \%$ of the land area of the southeast would be highly unlikely.

Further analysis of the other renewables resources (comparative cost, supplies, policies required) is beyond the scope of this study. 


\section{Planned transmission resources in Southeast}

As part of the analysis to understand the transmission issues related to transporting energy with SERC and for importing wind energy into the Southeast, EPRI contracted LCG Consultants to conduct a study using their UPLAN production simulation and transmission model. Available and planned transmission additions are based on several recent studies. The total inter-regional transmission capacity requirement, which is not currently in the plan, was assumed at a level for transporting renewable energy to achieve 15\% RPS in 2020. This chapter presents an overview of results related to transmission resources combining the UPLAN model approach and other available results on the eastern interconnection. Appendix A is a description of the UPLAN model.

\subsection{Introduction (UPLAN model)}

LCG Consulting has provided input to EPRI and ORNL to determine regional energy trading potential between SERC and adjacent regions under different RPS scenarios. In particular, LCG is to project how much renewable energy, especially wind power, can be transported to SERC from other areas in the Eastern Interconnection. LCG will be looking at the RPS in each region in 2020 and determine how much additional renewable capacity can be added to compensate for any shortage of the RPS requirements in SERC.

LCG applied there existing database for Eastern Interconnection for 2009 including all the generators and major inter-ties between the regions. This 2009 Eastern Interconnection database represents 7,159 generators and 131 transmission inter-ties. UPLAN was applied to simulate unit commitment and dispatch for the selected year to provide a preliminary estimate of transfers between the control areas, especially to SERC from all other areas.

LCG's Network Power Model (UPLAN) is an integrated electricity generation and transmission model developed to simulate both the behavior of market participants and the physical features of the electricity system. It projects detailed physical and financial operations of electricity markets conditions ranging from traditional regulation to today's post-restructuring competitive market structures. The model provides the consistent, structured framework, as well as the detailed quantitative inputs and results, required to evaluate the full implications of different fundamental drivers and market participant decisions.

UPLAN is a full network model designed for electricity market simulation, replicating the engineering protocols and market procedures of an operator, and captures the commercial activities, such as bidding, trading, hedging, and contracting, of all players in a restructured power market. The model performs coordinated marginal (opportunity) cost-based energy and ancillary service procurement, congestion management, full-fledged contingency analysis with Security Constrained Unit Commitment (SCUC) and Security Constrained Economic Dispatch (SCED).

UPLAN dispatch algorithm is capable of simulating all different types of generators such as thermal, hydro, wind and renewable, cogeneration and many other technologies. UPLAN can represent almost any kind of generation, transmission and a combination of loads. UPLAN has been used extensively to simulate and analyze such regional markets as PJM, New York, New England, MISO, ERCOT and California. 


\subsection{The Eastern Interconnection Database, 2009}

For this demonstrative analysis, LCG has developed a DC model for the Eastern Interconnection including New York, New England, PJM, MISO, SPP and SERC in the U.S. and Quebec, Ontario, New Brunswick, and Nova Scotia in Canada. For this version they made a reduced interconnection to FRCC. Each control area is represented and connected by inter-ties. The interties represent the transmission system and carry electricity between the control areas. The intracontrol area transmission lines are ignored because they do not contribute to the transfer of electricity between areas. The model includes all the generators and hourly loads of all the control areas in the regions mentioned. The Eastern Interconnect Model simulates the flows from and to neighboring areas and provides imports/exports and comparative price performance of a zone.

There has been considerable generation development in SERC since 1998. However, much of this generation has not contracted to serve load. According to the latest SERC survey, as of December 31, 2007, total generation (including uncommitted generation) connected to the transmission system in SERC was 266,622 MW, with an additional 2,314 MW of net projected additions planned to be connected by July 1, 2008. Over the period covered by the 2008 survey, generation capacity additions totaled 49,647 MW (Figure 6).

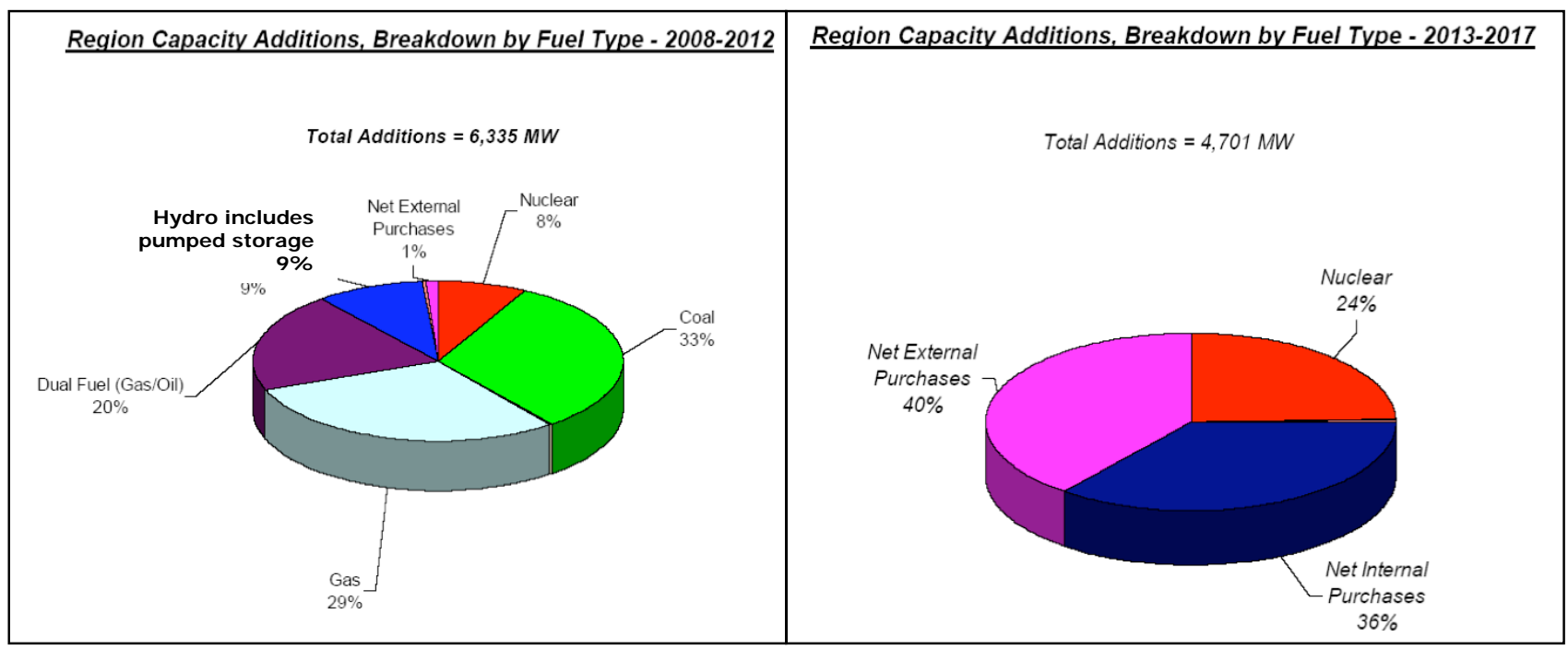

Figure 6. SERC Generation Development (Source: SERC Reliability Corporation Information Summary, July 2008)

In developing the transmission network, LCG makes reference to several sources including, for instance, the transfer limits assumed for 2007 to 2009 period in a study conducted by NPCC CP8 Working Group in 2007 as well as the non-simultaneous transfer capabilities from NERC 2004 Summer Assessment. Figure 7 illustrates the ability of the transmission network to transfer electricity from one area to another for a single demand and generation pattern. Different patterns of demand and generation cause variations in transfer capabilities on a day-to-day (or hour-to-hour) basis. 


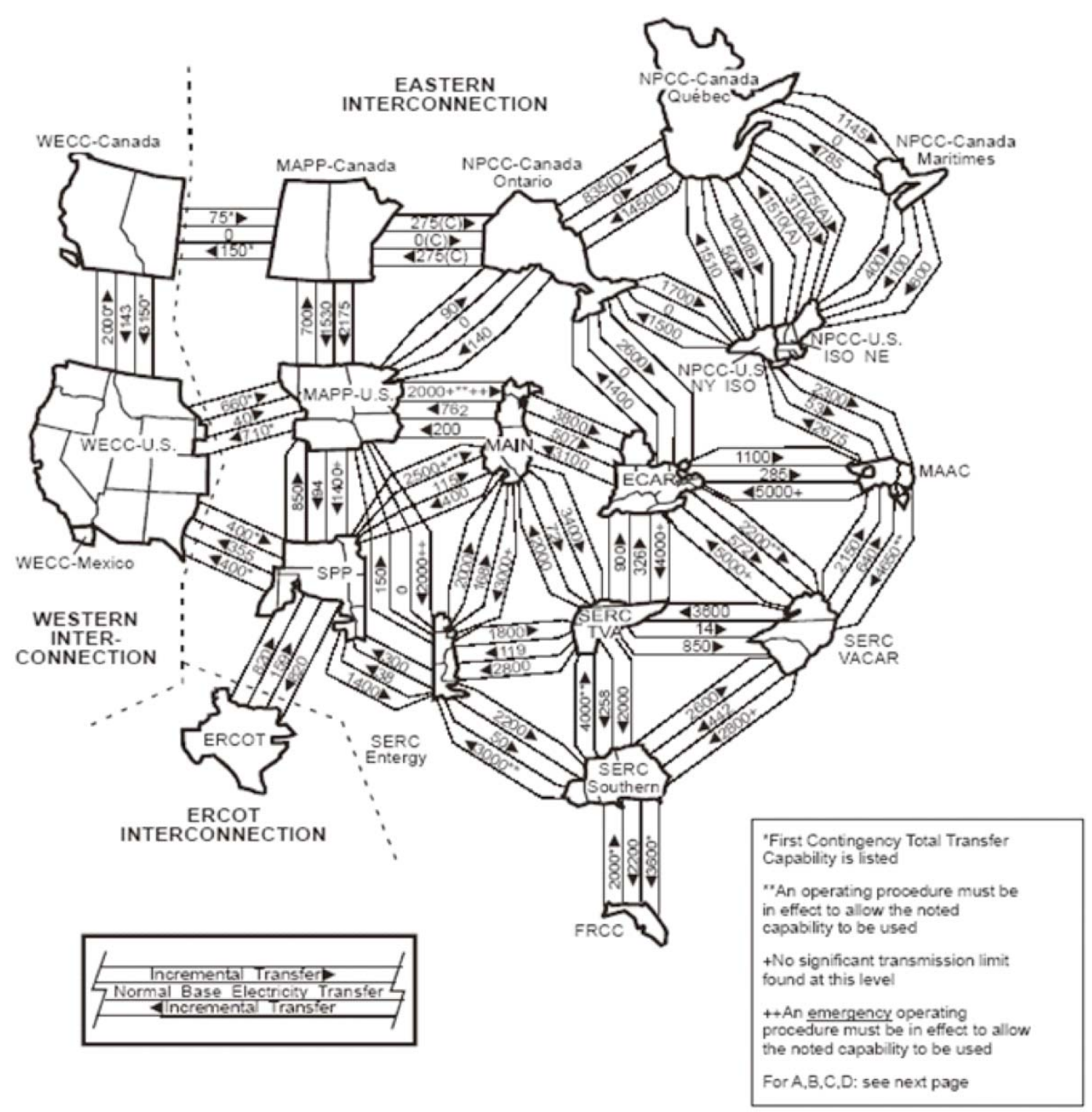

Figure 7. Normal Base Electricity Transfer and First Contingency Incremental Transfer Capabilities (Source: NERC 2004 Summer Assessment)

In addition, SERC systems have developed a robust transmission system with more than 100 transmission connections to its neighbors to the north and west. The planned transmission expansion (line additions) at $230 \mathrm{kV}$ and above in SERC represents approximately 20 percent of all transmission expansion in the U.S. over the next ten years. 


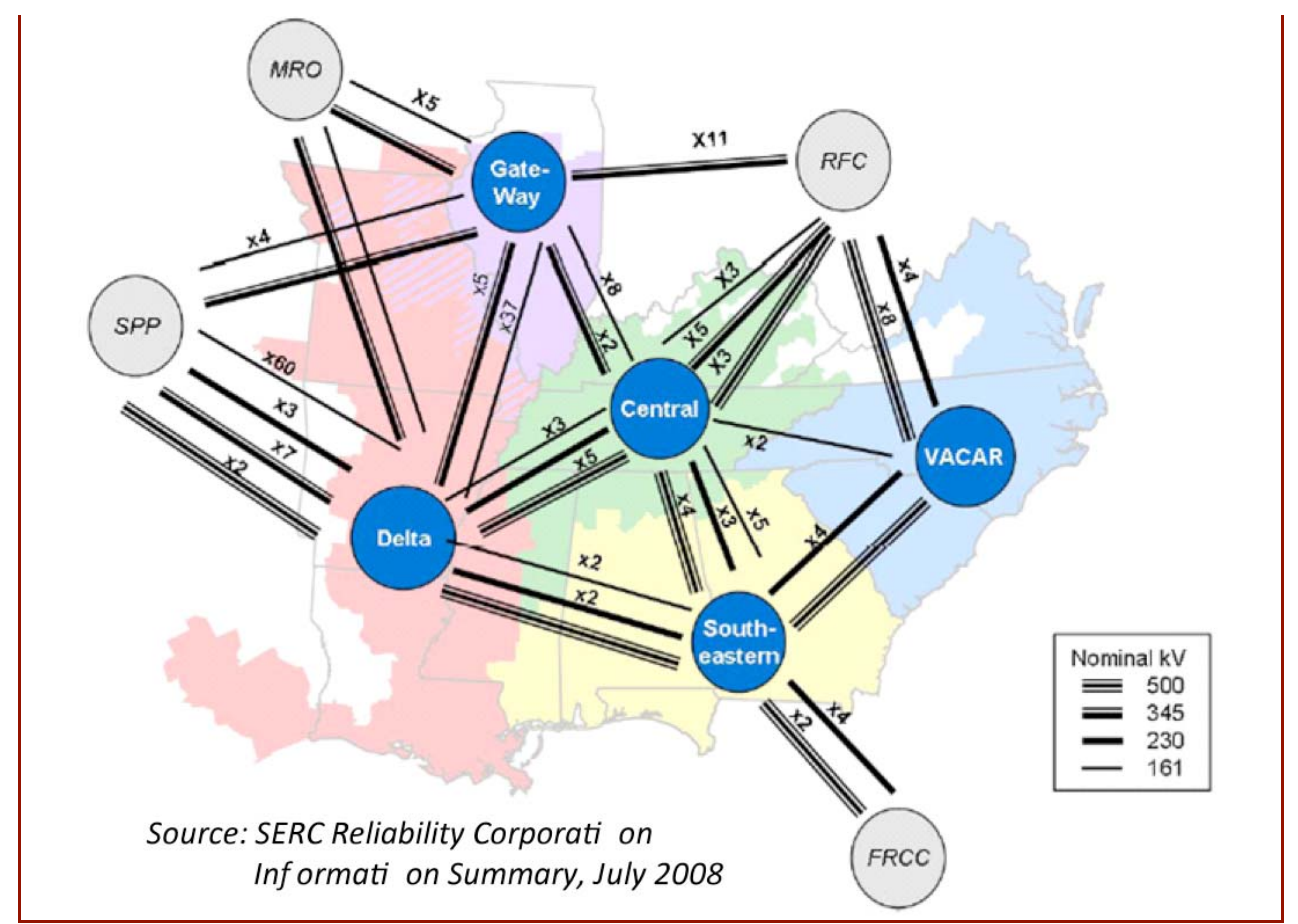

Figure 8. SERC Inter- and Intra-Regional Interconnections

Table 10 is a summary of the resources and loads of the Eastern Interconnection in 2009. The peak demand and total capacity are further illustrated in Figure 9, Figure 10, and Figure 11.

Table 10. Summary of Resources and Loads in Eastern Interconnect (2009)

\begin{tabular}{|c|c|c|c|c|c|c|c|c|c|c|}
\hline Region & $\begin{array}{l}\text { Wind } \\
\text { (WM) }\end{array}$ & $\begin{array}{l}\text { Hydro } \\
\text { (MW) }\end{array}$ & $\begin{array}{l}\text { Nuclear } \\
\text { (MW) }\end{array}$ & Coal (MW) & $\begin{array}{l}\text { Natural } \\
\text { Gas } \\
\text { (MW) }\end{array}$ & $\begin{array}{c}\text { Oil } \\
\text { (MW) }\end{array}$ & $\begin{array}{l}\text { Other } \\
\text { (MW) }\end{array}$ & $\begin{array}{c}\text { Total } \\
\text { Capacity } \\
\text { (MW) }\end{array}$ & $\begin{array}{l}\text { Annual } \\
\text { Peak } \\
\text { Demand } \\
\text { (MW) } \\
\end{array}$ & $\begin{array}{c}\text { Annual Energy } \\
\text { Demand } \\
\text { (GWh) }\end{array}$ \\
\hline SERC & 29 & 16,777 & 29,743 & 71,580 & 80,630 & 4,963 & 1,627 & 205,348 & 179,069 & 984,884 \\
\hline PJM & 1,356 & 7,342 & 31,566 & 64,781 & 52,562 & 13,163 & 10,532 & 181,302 & 137,361 & 743,425 \\
\hline MISO & 7,850 & 8,292 & 11,589 & 80,820 & 44,193 & 5,289 & 1,487 & 159,520 & 105,574 & 607,152 \\
\hline SPP & 2,915 & 2,944 & 1,235 & 26,436 & 31,276 & 1,580 & 58 & 66,443 & 47,358 & 222,432 \\
\hline NEW YORK & 2,008 & 5,838 & 5,263 & 2,837 & 17,452 & 9,072 & 682 & 43,151 & 34,326 & 168,684 \\
\hline NEW ENGLAND & 240 & 3,633 & 4,479 & 2,839 & 17,429 & 5,801 & 1,818 & 36,240 & 27,914 & 136,805 \\
\hline TOTAL & 14,398 & 44,826 & 83,874 & 249,291 & 243,542 & 39,868 & 16,204 & & & \\
\hline
\end{tabular}




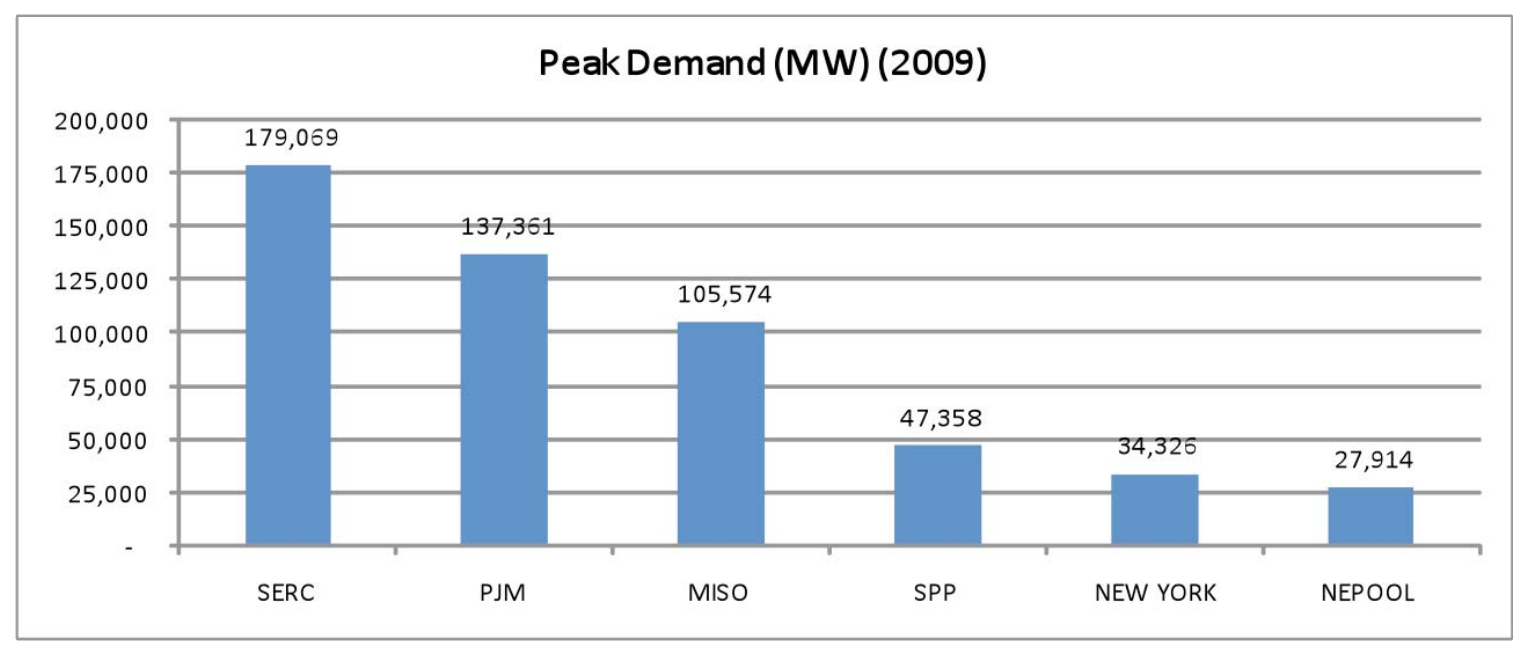

Figure 9. 2009 Peak Demand (MW) by Region

Total Capacity By Fuel Type (2009)

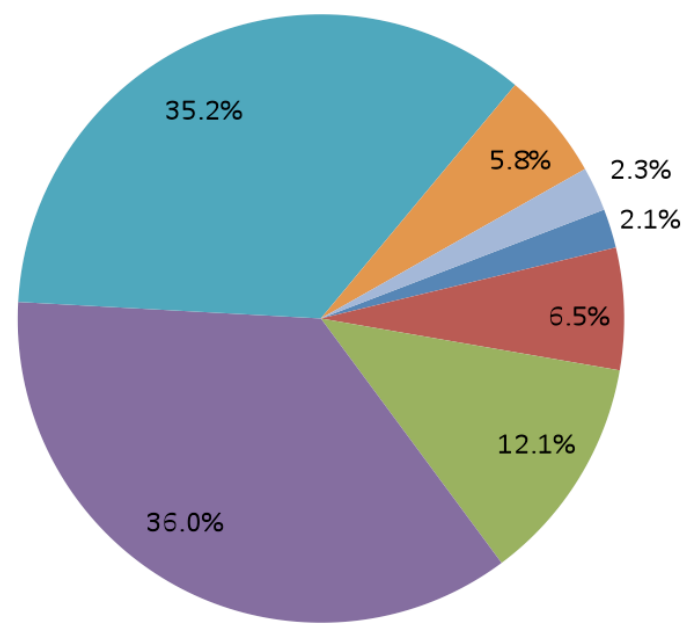

$$
\begin{aligned}
& \text { Wind } \\
& \text { Hydro } \\
& \text { Nuclear } \\
& \text { CoalBased } \\
& \text { Natural Gas } \\
& \text { Oil } \\
& \text { Other }
\end{aligned}
$$

Figure 10. Breakdown of Capacity by Fuel Type in Eastern Interconnect (2009) 
Total Capacity By Region (2009)

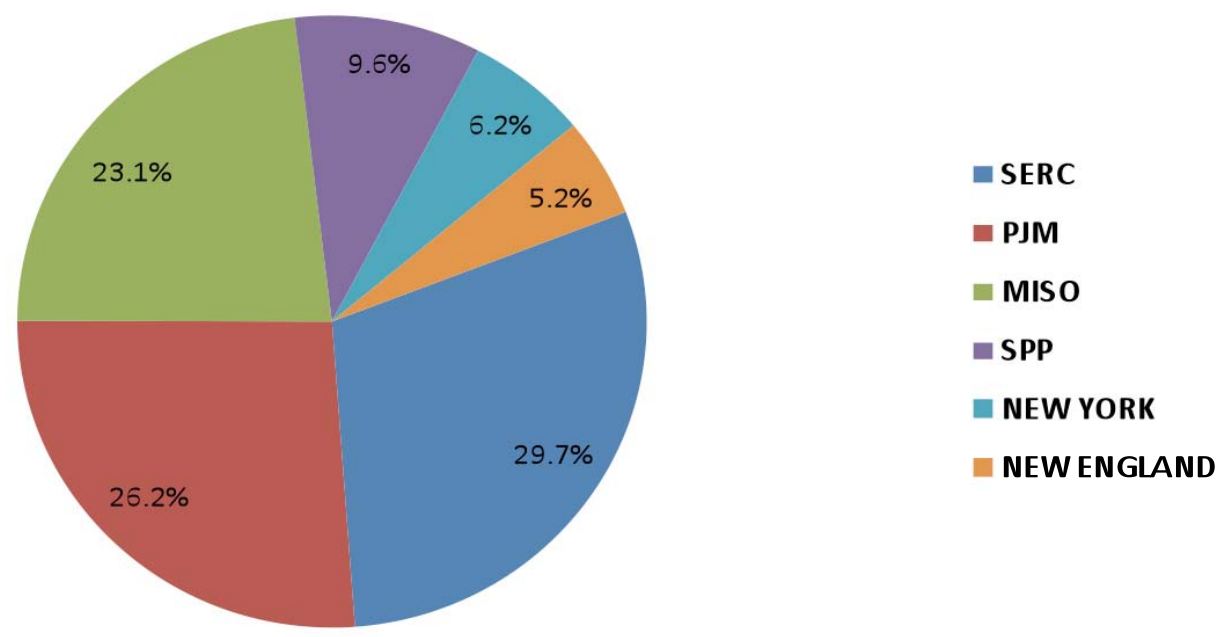

Figure 11. Breakdown of Capacity by ISO/Regions Eastern Interconnect (2009)

For this study we have developed an expansion plan to assess the available capacity for the various regions in 2020. This expansion plan takes into account generation and transmission projects that have been already approved and the proposed ones that are currently under ISO evaluation. Below is a brief description on the methodology used to develop generation and transmission expansion plans for 2020.

\subsubsection{Generation Expansion Methodology}

For each region/ISO, the interconnection agreements were studied carefully. The projects with interconnection status approved or under construction were selected and added in the respective zones. The units with planned retirement dates before the end of study period are not considered in the simulation.

Since the simulations were performed in order to model the RPS requirements, the majority of the capacity addition was contributed by wind generators in SPP, MISO (mostly the MAPP and some from MAIN) and PJM (ECAR and MAAC). Note that all three are quite limited. Even SPP and MISO, with significant wind resources, did not contribute very much. This is because of limited demand in these regions and lack of transmission in the current plan for exporting wind to the Southeast and Florida regions. To meet the 15\% RPS by 2020, the wind generation expansion plan was designed based on regional requirements, existing wind capacity, and planned wind generation plants with signed/approved interconnection agreements.

\subsubsection{Transmission Expansion Methodology}

Similar to the generation expansion methodology, the proposed interconnection agreements for transmission were studied carefully for each ISO/region and the approved ones were included in the test scenarios (Table 11). The stable expansion plan was reached after running various simulation cases or scenarios on UPLAN. The results from these simulations were consistent in terms of the expected flows, prices and the reserve margins. There was no unserved energy in the 
system. The simulation results include renewable energy both imported into the SERC and as REC, so that the region meets RPS and federal requirements.

The network was based on 2007 series MMWG 2009 load flow case published by FERC. A transmission expansion plan was created using transmission upgrades published by MISO, PJM, NYISO, NEPOOL, and SPP which is summarized in Table 11.

Table 11. Transmission Expansion as per Interconnection agreements (2020)

\begin{tabular}{|l|r|}
\hline \multicolumn{1}{|c|}{ Project Name } & \multicolumn{1}{|c|}{$\begin{array}{c}\text { Capacity } \\
\text { (MW) }\end{array}$} \\
\hline Linden VFT Inter-Tie (New York) & 300 \\
\hline Maple River to Alexandria SS (MISO) & 2,085 \\
\hline Baldwin to Rush Island (MISO) & 1,795 \\
\hline AB Brown to Gibson (Duke) (MISO) & 1,430 \\
\hline AB Brown to Reid (BREC) (MISO) & 1,430 \\
\hline Gardner Park (New Weston) to HWY 22 (formerly Central Wisconsin) (MISO) & 1,775 \\
\hline Susquehanna - Roseland (PJM) & 2,500 \\
\hline Amos - Midpoint (PJM) & 6,500 \\
\hline Meadowbrook - Loudoun (PJM) & 3,465 \\
\hline Calvert Cliff S - Salem (PJM) & 2,810 \\
\hline Orrington ME and BostonMA (New England) & 1,000 \\
\hline Maine Yankee Substati on, South Boston Substati on (New England) & 1,000 \\
\hline
\end{tabular}

Table 12 is a summary of the resources and loads of the Eastern Interconnection in 2020. The peak demand and total capacity are further illustrated in Figure 12, Figure 13, and Figure 14.

Table 12. Summary of Resources and Loads in Eastern Interconnect (2020)

\begin{tabular}{|c|c|c|c|c|c|c|c|c|c|c|}
\hline Region & $\begin{array}{l}\text { Wind } \\
\text { (WM) }\end{array}$ & $\begin{array}{l}\text { Hydro } \\
\text { (MW) }\end{array}$ & $\begin{array}{c}\text { Nuclear } \\
\text { (MW) }\end{array}$ & Coal $(\mathrm{MW})$ & $\begin{array}{c}\text { Natural } \\
\text { Gas } \\
\text { (MW) }\end{array}$ & $\begin{array}{c}\text { Oil } \\
\text { (MW) }\end{array}$ & $\begin{array}{l}\text { Other } \\
\text { (MW) }\end{array}$ & $\begin{array}{c}\text { Total } \\
\text { Capacity } \\
\text { (MW) }\end{array}$ & $\begin{array}{l}\text { Annual } \\
\text { Peak } \\
\text { Demand } \\
\text { (MW) }\end{array}$ & $\begin{array}{l}\text { Annual Energy } \\
\text { Demand } \\
\text { (GWh) }\end{array}$ \\
\hline SERC & 9,742 & 17,860 & 37,072 & 82,012 & 88,985 & 5,026 & 1,627 & 242,324 & 210,097 & $1,167,541$ \\
\hline PJM & 44,788 & 7,822 & 34,066 & 65,307 & 54,702 & 13,333 & 10,792 & 230,810 & 158,614 & 865,131 \\
\hline MISO & 40,265 & 8,292 & 11,589 & 84,548 & 52,177 & 5,259 & 1,487 & 203,617 & 122,574 & 713,818 \\
\hline SPP & 11,743 & 2,492 & 1,235 & 19,264 & 31,027 & 1,517 & 58 & 67,336 & 50,741 & 240,018 \\
\hline NEW YORK & 13,527 & 5,694 & 5,433 & 2,837 & 20,452 & 8,181 & 712 & 56,835 & 38,639 & 192,179 \\
\hline NEW ENGLAND & 11,117 & 4,933 & 2,913 & 3,103 & 19,705 & 4,990 & 2,772 & 49,533 & 30,118 & 148,265 \\
\hline Grand Total & 131,182 & 47,094 & 92,307 & 257,070 & 267,048 & 38,306 & 17,448 & & & \\
\hline
\end{tabular}




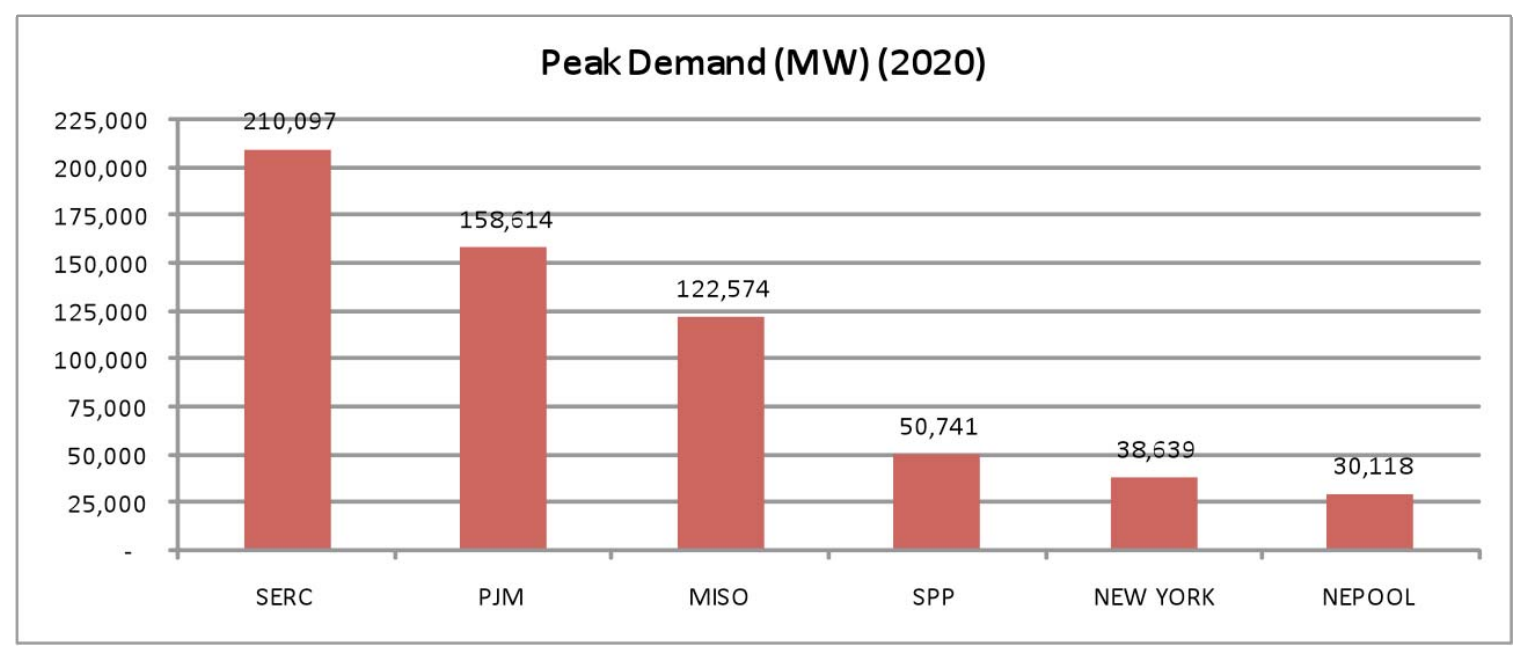

Figure 12. 2020 Peak Demand (MW) by Region

\section{Total Capacity By Region (2020)}

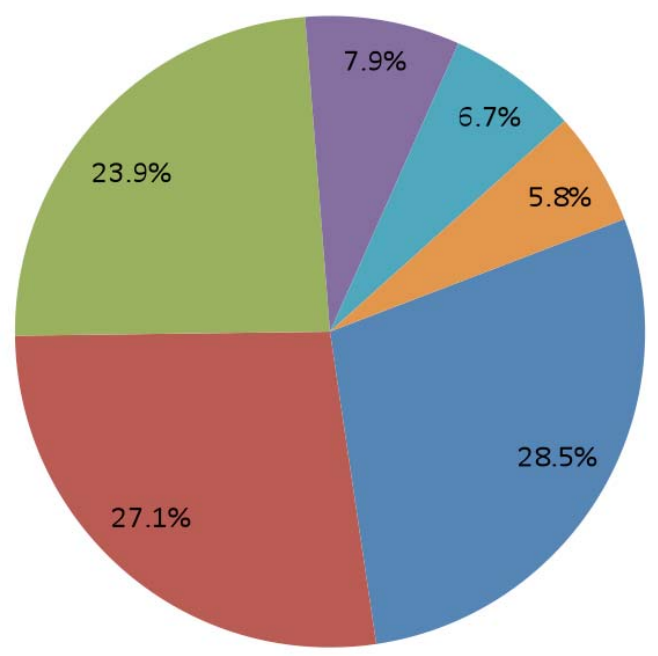

$$
\begin{aligned}
& =\text { SERC } \\
& =\text { PJM } \\
& =\text { MISO } \\
& \text { SPP } \\
& \square \text { NEW YORK } \\
& \square \text { NEW ENGLAND }
\end{aligned}
$$

Figure 13. Total Capacity by Region (2020) 
Total Capacity By Fuel Type (2020)

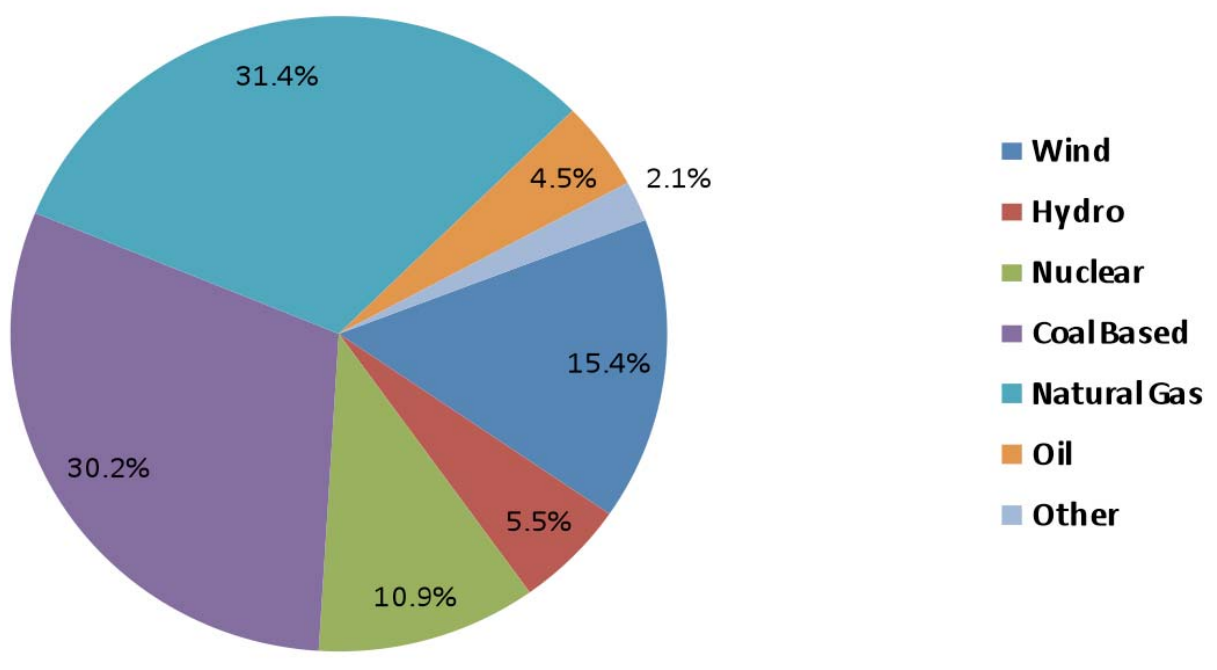

Figure 14. Total Capacity by Fuel Type in the studied Eastern Interconnection (2020)

With the total imports from MISO, PJM and SPP (Table 13), considering the transmission constraints, around 3.2\% of SERC's demand and with its own renewable generation accounting up to $2.5 \%$, SERC can meet only about $6 \%$ of its energy requirements using renewable sources.

Table 13. Annual Zonal Flows for SERC

\begin{tabular}{|c|c|c|}
\hline \multicolumn{3}{|c|}{ SERC Annual Flows (GWh) -2009 } \\
\hline SPP & MISO & PJM \\
\hline $\begin{array}{c}\text { Exports to } \\
\text { SERC }\end{array}$ & $\begin{array}{c}\text { Exports to } \\
\text { SERC }\end{array}$ & $\begin{array}{c}\text { Exports to } \\
\text { SERC }\end{array}$ \\
\hline 9,131 & 13,428 & 2,983 \\
\hline
\end{tabular}

\begin{tabular}{|c|c|c|}
\hline \multicolumn{3}{|c|}{ SERC Annual Flows (GWh) -2020 } \\
\hline SPP & MISO & PJM \\
\hline $\begin{array}{c}\text { Exports to } \\
\text { SERC }\end{array}$ & Exports to & Exports to \\
SERC & SERC \\
\hline 12,900 & 15,899 & 3,841 \\
\hline
\end{tabular}

The zonal flow into SERC may be accounted toward its RPS requirement provided other regions exceed their own requirement, which is assumed to be $15 \%$. In Table 14, we present the actual wind generation.

Table 14. Annual Regional Wind Generation (2020)

\begin{tabular}{|l|r|r|}
\hline \multicolumn{1}{|c|}{ Region } & $\begin{array}{c}\text { Wind } \\
\text { Generati on } \\
\mathbf{2 0 2 0} \text { (TWh) }\end{array}$ & $\begin{array}{c}\text { Wind Generati o } \\
\text { as \% of Demand }\end{array}$ \\
\hline SERC & 29.87 & $2.56 \%$ \\
\hline PJM & 151.58 & $17.52 \%$ \\
\hline MISO & 144.06 & $20.18 \%$ \\
\hline SPP & 45.76 & $19.07 \%$ \\
\hline NEW YORK & 27.25 & $14.18 \%$ \\
\hline NEW ENGLAND & 23.70 & $15.98 \%$ \\
\hline
\end{tabular}


Note that Table 14 only includes the amount of wind generation within the region without giving any credits for imports. There is some excess wind developed in MISO, PJM, and SPP.

However, the excess wind that is expected to be developed in these regions is not sufficient to cover the deficiency in SERC. 


\section{Alternative means to meet RPS goal in SE}

Renewable energy resources are very location specific and the most economical deployment, particularly for wind energy, is generally not near population centers. This is illustrated in Figure 15 showing wind resources in blue and population centers in red and yellow. There is very little resource in the Southeast. If there were no transmission constraints in the eastern interconnect, the most economic deployment of wind would be in the Midwest with the energy transported to the east.

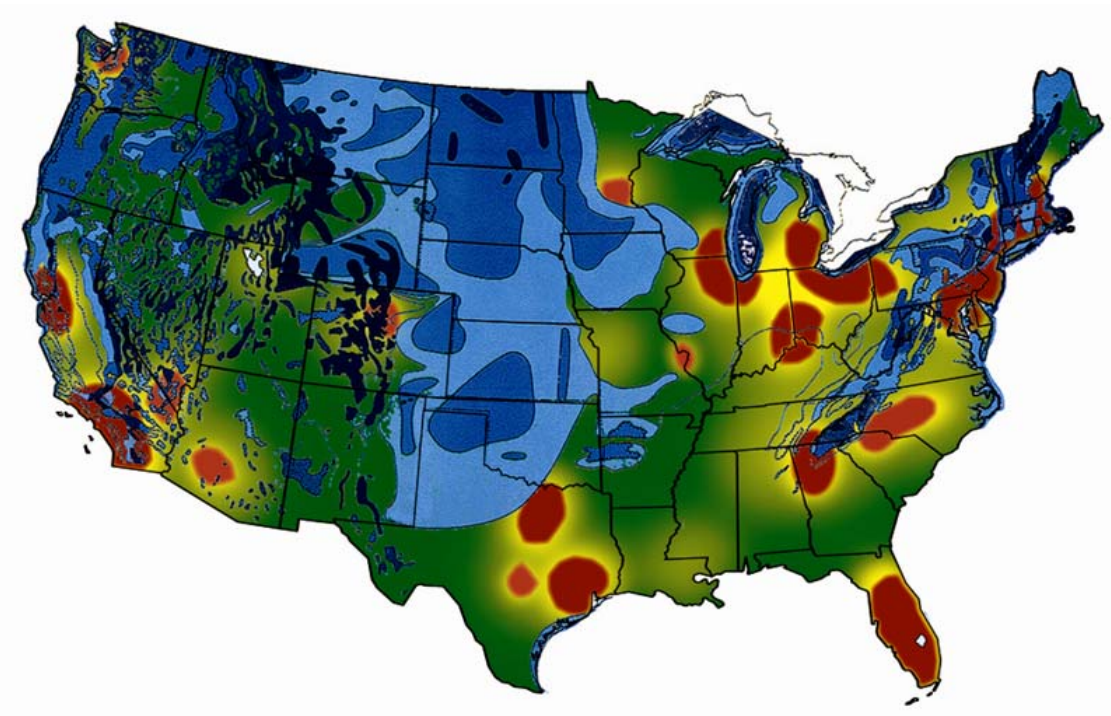

Figure 15. Wind Resources Relative to Population Centers.

Results in the JCSP and EWITS studies identify west to east transfers of wind energy that are primarily via upper Midwest to the eastern coast. Some energy transfer is expected to come from SPP to SERC Delta, and also via the Midwest to SERC Central. However, these transfers are relatively small compared to the available wind resources and compared to what would be needed to meet an RPS in the SERC and Florida regions.

\subsection{RPS expectation with regional balancing of supply/demand}

Federal policies, in particular related to $\mathrm{CO}_{2}$ and RPS, are expect to affect the regional cost of electricity based on models that assume the historical regional balancing of supply and demand. One policy scenario is the new Bingaman RPS requirement. In its current configuration the bill allow trading of renewable energy credits in order to meet RPS requirements. Therefore areas of the country with more abundant renewable resources are expected to over-produce in order to earn and sell credits to other areas.

Under this arrangement, utilities in the south would need to purchase RECs from other regions. For example based on EPRI's NESSIE model, with only an RPS policy (no carbon policy) the Southeast would requires 1017 TWh in 2020, and the electricity production from renewable resources would be $\sim 113 \mathrm{TWh}$, which is $91 \mathrm{TWh}$ short of the $20 \%$ RPS. External generation would provide the difference. In Florida the same EPRI model and scenario estimates that demand in 2020 is $282 \mathrm{TWh}$, and production from renewable resources is $9 \mathrm{TWh}$. With a $20 \%$ 
RPS goal of $56 \mathrm{TWh}$, internal production from renewable energy of $48 \mathrm{TWh}$ is short of the goal. Applying the cap REC price of $3 \phi / \mathrm{kWh}$ (the ceiling in the Bingaman bill), there would be an estimated outflow of roughly \$2.7 Billion from SERC and \$1.4 Billion from Florida in 2020.

In order to better understand some of the different policy implications the EPRI NESSIE model was used to look first at the national picture and then for the Southeast and neighboring regions. Three policy cases were considered as summarized in Table 15.

Table 15. Three Possible Policy Scenarios, Source EPRI Report 1015805, March 2009 "Role of Future Generation Options for the U.S. Electric Sector"

\begin{tabular}{|l|c|c|c|c|}
\hline \multicolumn{1}{|c|}{ Future Scenario } & Name & PTC & RPS & $\mathbf{C O}_{2}$ Price \\
\hline No new policy & BAU & Yes & No & No \\
\hline Federal RPS & RPS & Yes & Yes & No \\
\hline Federal carbon policy & CO2 & Yes & No & Moderate \\
\hline
\end{tabular}

- Load growth based on AEO 2008

- RPS policy assumptions based on the revised Bingaman Bill

- For carbon case, $\mathrm{CO} 2$ price in 2015 is approximately $\$ 27$ per ton

- Natural gas prices vary from $\$ 4.91$ to $\$ 7.28 / \mathrm{MMBtu}$

\subsubsection{National RPS Levels with different Policies}

Results of modeling show that the economic deployment of renewable varies significantly depending on policies. The Figure 16, showing periods from 2010 to 2050, indicates that nationally a $\mathrm{CO} 2$ policy results in the highest deployment of renewable resources. It will also lead to a higher cost of electricity compared to the no policy or the RPS policy case.

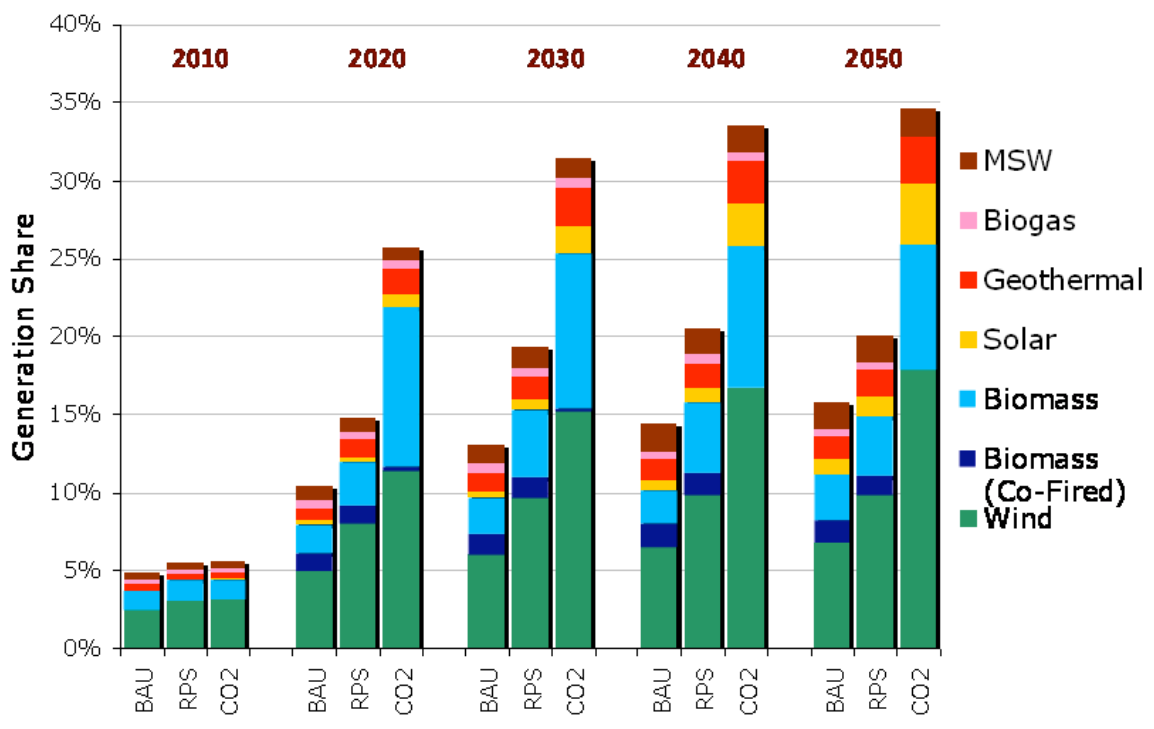

Figure 16. Renewable Share of Total Generation for Three Scenarios 
A comparison of how national electricity demand would be met in the three different policy cases is provided in Figure 17. Note that the same demand is shown for each policy. A simplifying assumption was applied, where demand elasticity is not considered in the policy comparisons.

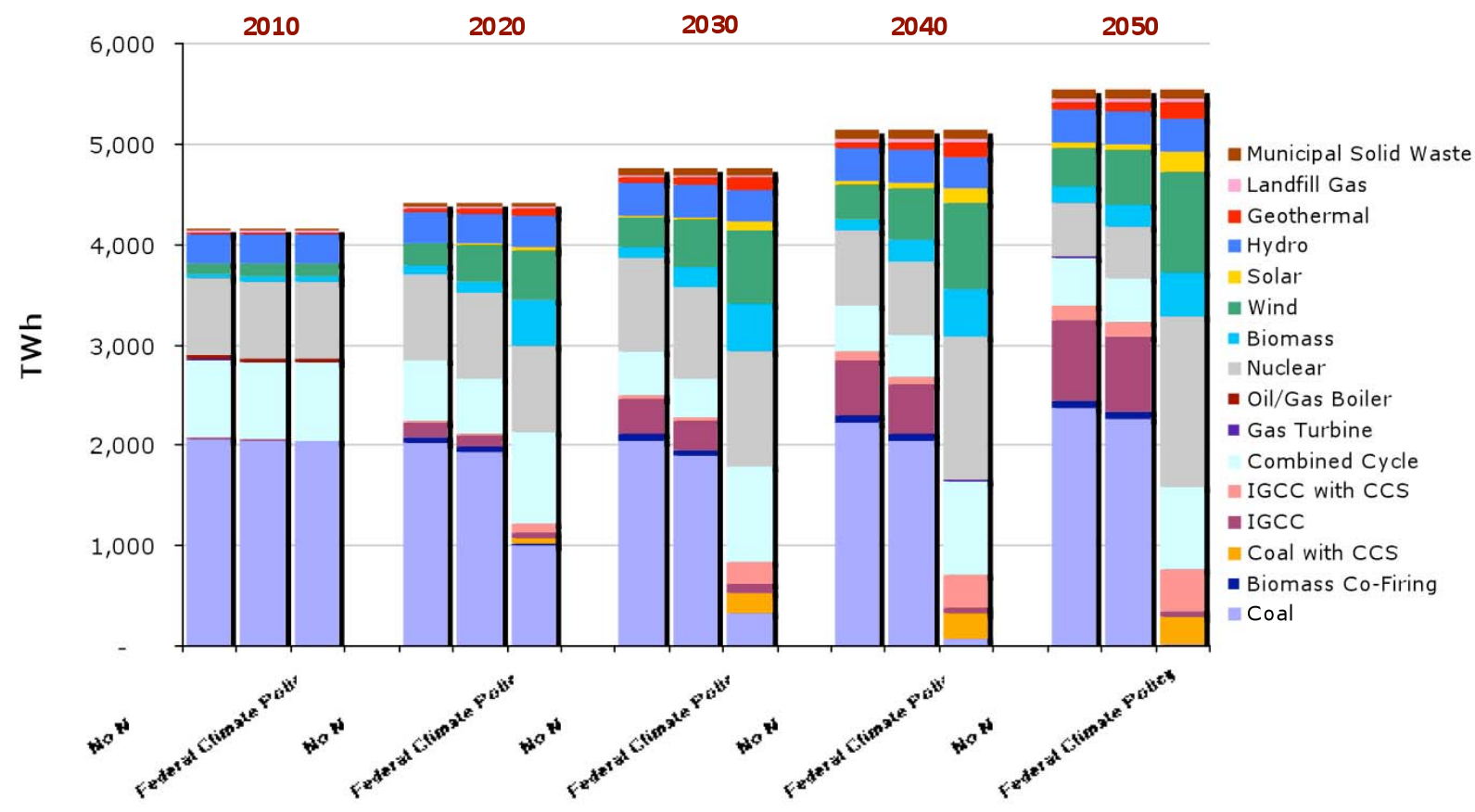

Figure 17. US Annual Electricity Generation under Different Scenarios (TWh)

NESSIE models the U.S. electric sector by carrying thirteen separate NERC regions. Nine of the 13 regions make up the Eastern interconnection. These regions are shown in Figure 1 above.

\subsubsection{Eastern Interconnect and SE RPS Potential with different Polices}

Modeling future scenarios for a large electric system depends on many, often subtle, factors in addition to the scenario assumptions. Capacity expansion and system operation are sensitive to load patterns, existing capacity, and commodity prices for both fuels and emission allowances. These vary from region to region.

In addition, renewable technologies depend on the extent and quality of wind, solar insolation, moving water suitable for hydro, and underground thermal. Also, the cost of delivered biomass fuel can vary. Differences in renewable resource availability represent an important factor for understanding the future LCOE that determines new capacity additions. In addition, the resource quality differences and the availability with respect to time of day (energy output profiles) help shape the production results for the regional systems. The deployment of renewable energy is expected to vary significantly from one region to another as shown in Figure 18. Also affecting the deployment is regional demand and competing generation options in a region. 


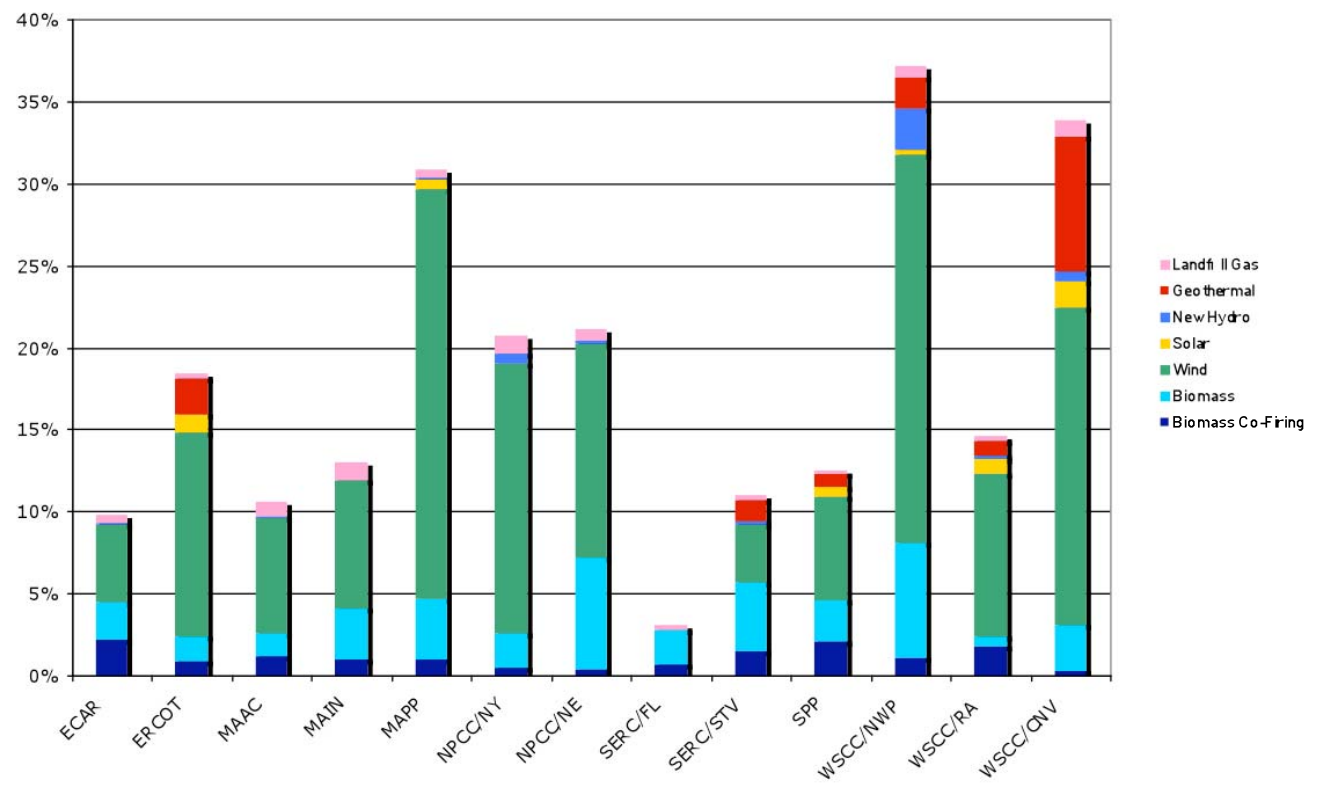

Figure 18. Regional Variation in Renewable Generation, RPS Policy Case (2020)

When considering where SERC/STV and Florida might import additional renewable energy the only apparent option in the RPS policy case shown above, is MAPP. However, most of the excess energy in MAPP and MAIN is spoken for by the east coast markets in MAAC, including PA, NJ, MD and Northern Virginia. There is abundant wind energy in SPP, however, other low cost generation options make wind investments less attractive. Also the relative size of electricity demand in the SE presents an additional challenge. As show in Figure 19 the SE plus Florida will consume about $\sim 1300$ TWh in 2020 , which is more than $30 \%$ of the total consumption in the US. 


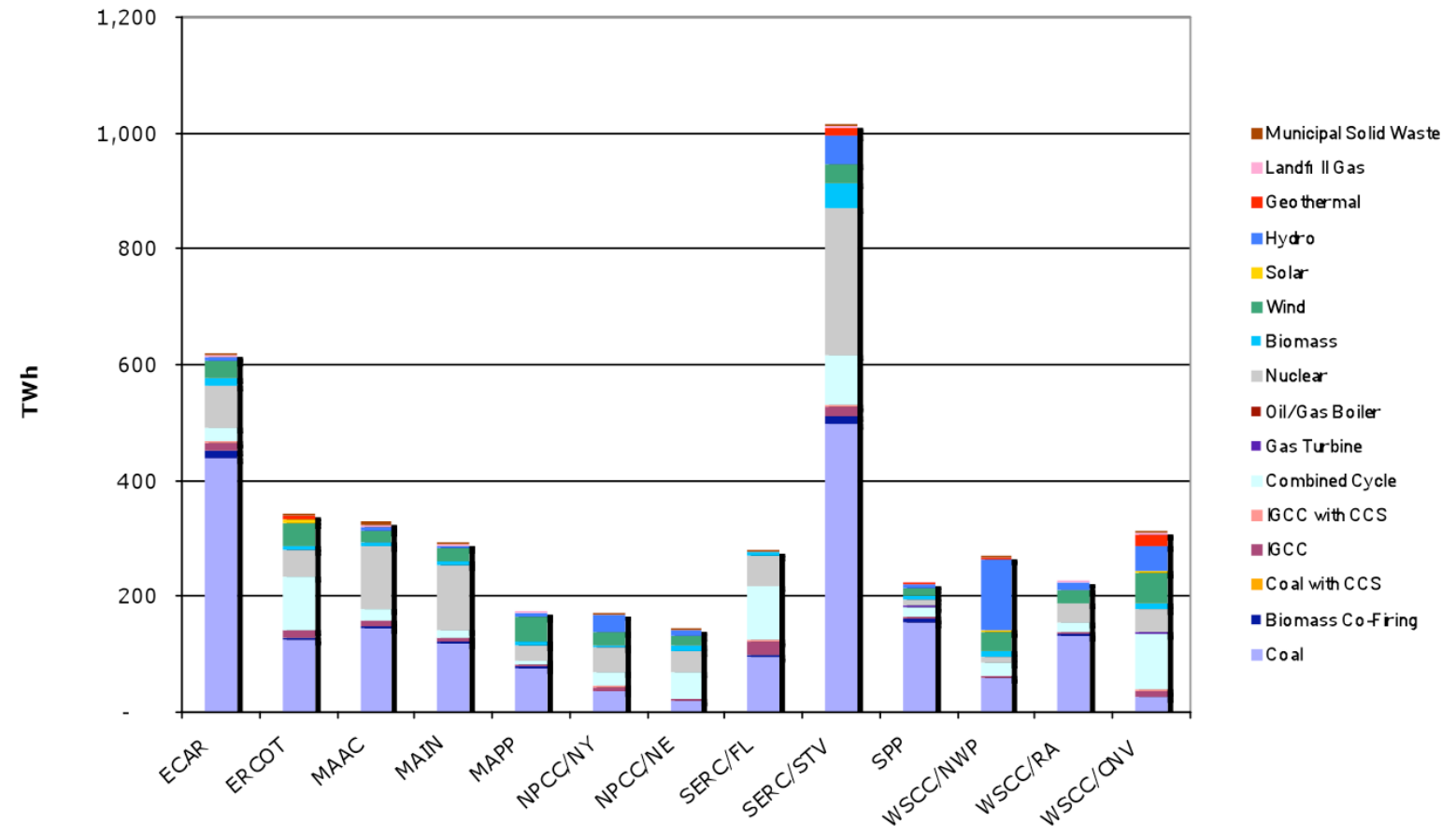

Figure 19. Regional Electricity Generation, RPS Policy Case 2020

The picture is expected to change significantly in all regions if there is a climate policy compared to the RPS case. For example in SPP almost three times more wind is deployed in the climate policy case than in the RPS case, see Figure 20.

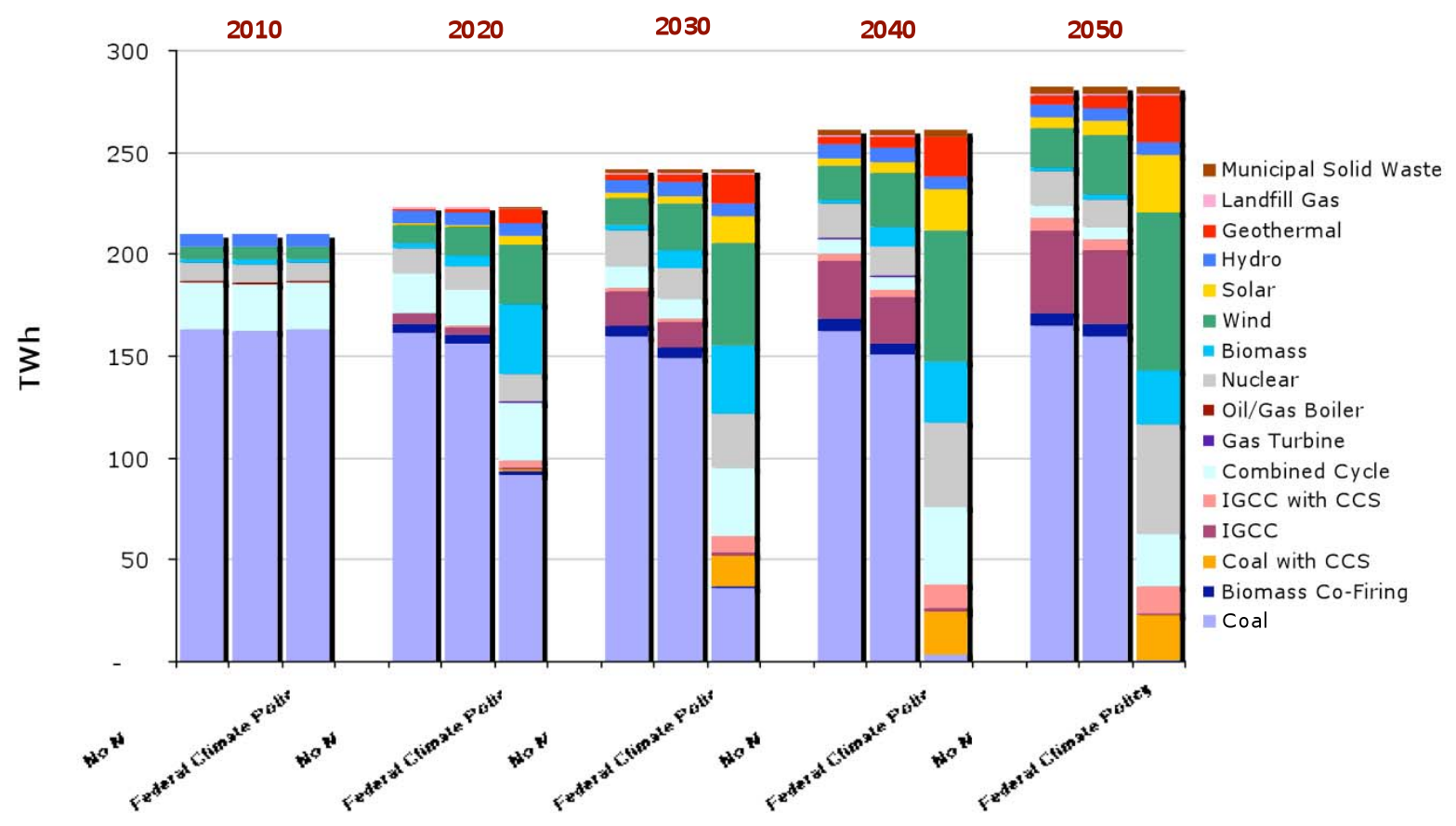

Figure 20. SPP Generation with no policy or federal RPS or federal climate policy 
The increase of wind generation capacity in SPP occurs without any expectation for export to other regions. Since SPP is only harvesting about $1 \%$ of the wind resources, it is apparent that building for export could make a big difference in capacity expansion and transfer of wind energy to the SE. There is also an expected change in the deployment of renewable energy in all regions of the Eastern Interconnection if a $\mathrm{CO}_{2}$ policy is enacted. Figure 21 shows the changes in generation in SERC and Figure 22 shows how the policy affects the cost of electricity in SPP, SERC/FL and SERC/STV.

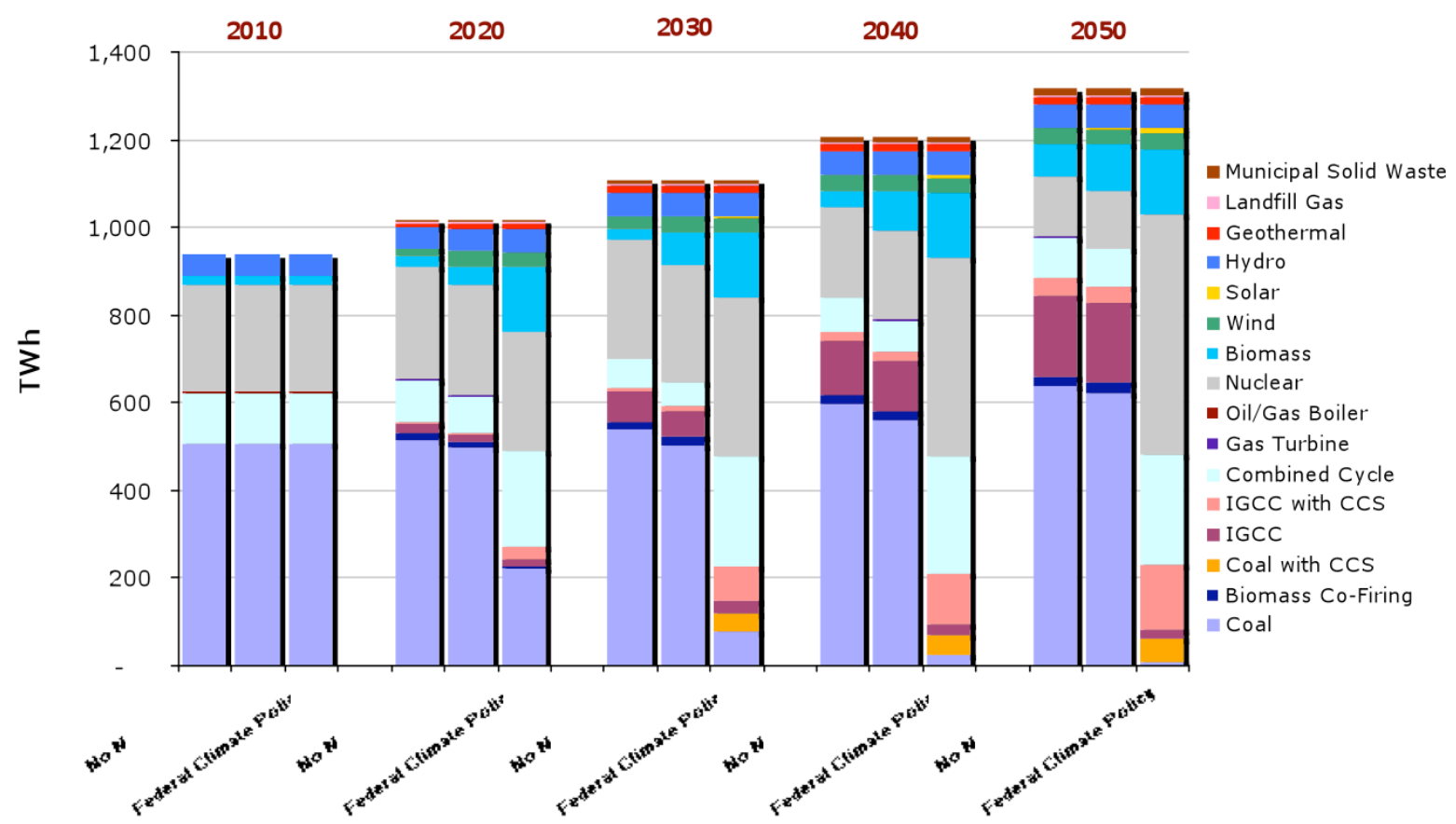

Figure 21 SERC Generation with no policy or federal RPS or federal climate policy

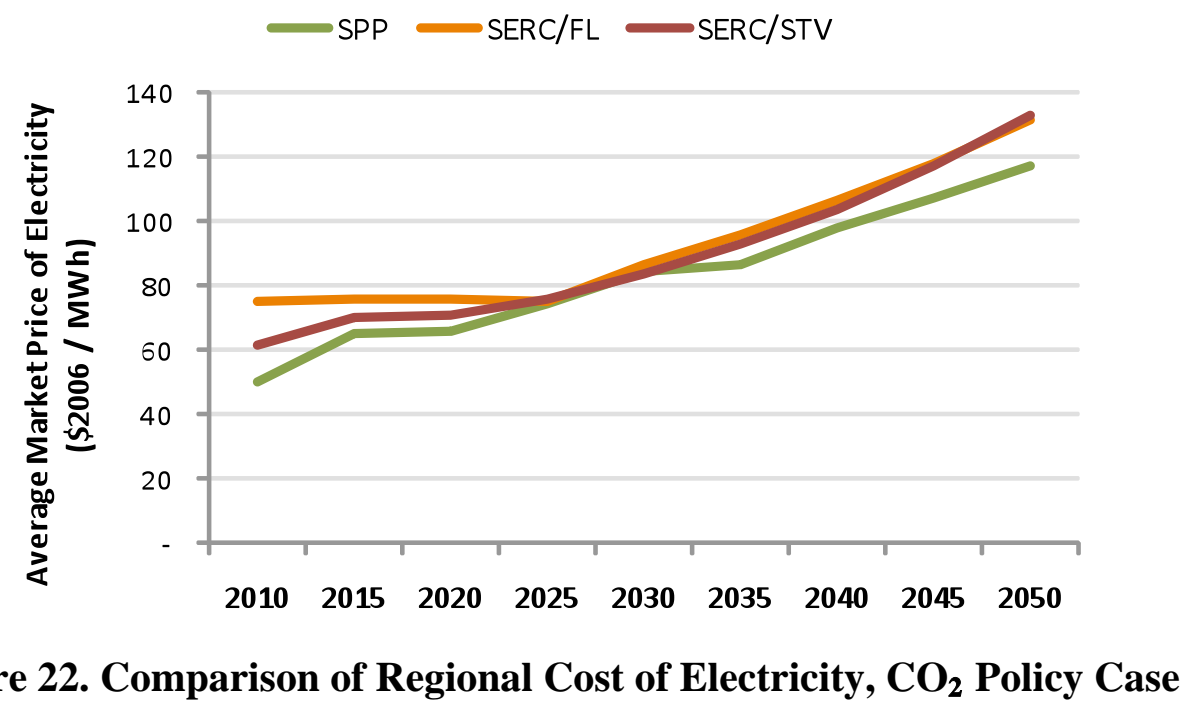


For the $\mathrm{CO}_{2}$ Policy Case market prices from 2010 to 2050 for three regions; the levelized prices for the three regions are \$69.58 per MWh in SPP, \$75.62 in SERC/STV, and \$81.97 in SERC/FL. These regional price differences are important for such metrics as customer satisfaction, asset values, and capacity retirements. As shown in the Figure lower prices in SPP early in the time horizon reflect good access to fuel markets and lower coal and natural gas prices; later, access to plentiful, high-quality renewable resources-especially wind, solar, and geothermal-provides an advantage as the $\mathrm{CO}_{2}$ price accounts for a larger fraction of the wholesale price. Over the long run, the SERC/STV and SERC/FL have similar price trajectories reflecting similar fuel costs and renewable resource bases. However, SERC/STV has a more economic mix in the early years, which leads to the lower levelized market price.

There are more significant impacts of $\mathrm{CO}_{2}$ policy in coal burning regions such as ECAR. In this case the cost of electricity in 2030 more than doubles from the no policy case, $\$ 40.50$ per MWh to $\$ 89.50$ per $\mathrm{MWh}$ with a moderate $\mathrm{CO}_{2}$ policy. The cost of the RPS, without $\mathrm{CO}_{2}$, policy is estimated to be $\$ 45.16 / \mathrm{MWh}$. Figure 23 show the significant change in the generation mix in ECAR depending on the policy.

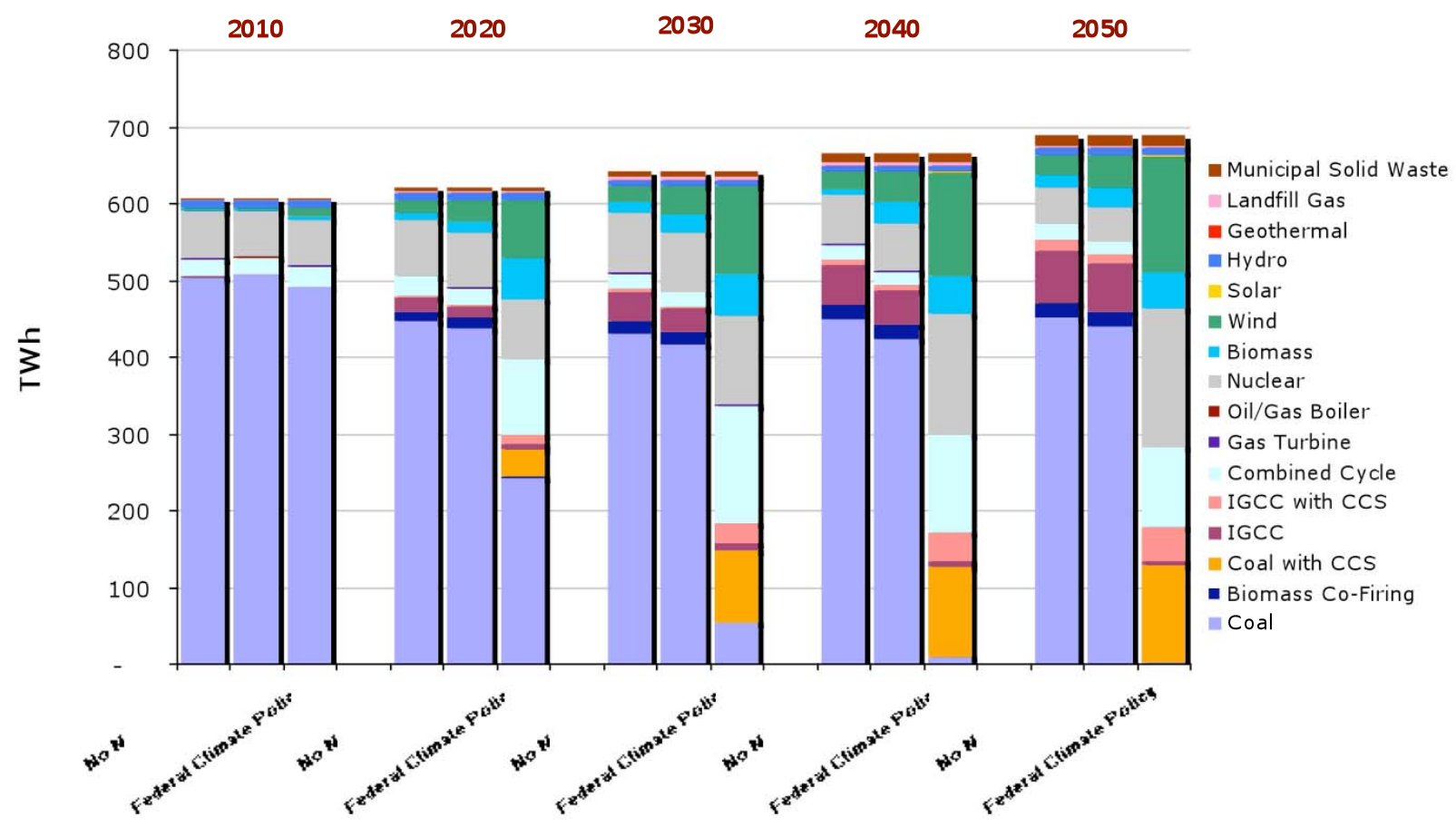

Figure 23 ECAR Generation with no policy or federal RPS or federal climate policy

\subsection{Other Studies}

There are several studies either completed or currently being carried out by other groups. Two of these are looking at the interconnection needs to meet large wind transfers in the eastern interconnections.

The Joint Coordinated System Plan (JCSP 2008) analysis is "a conceptual regional transmission and generation system plan for a large portion of the Eastern Interconnection in the United 
States, developed with the participation of most of the major transmission operators in the Eastern Interconnection. This initial effort looks at two scenarios that expand transmission and generation opportunities between 2008 and 2024 - a Reference Scenario and a 20\% Wind Energy Scenario in support of the U.S. Department of Energy's Eastern Wind Integration and Transmission Study."

The analysis was a collaborative project between the Midwest ISO, SPP, PJM, TVA, MAPP, and some other members of SERC. The New York ISO and ISO New England participated as well, but later rejected the results because they felt more of their power would come from Canada than across the Midwest. While power flows to the southeast were analyzed, details on the amounts to the different subregions and to Florida were not examined. Figure 24 below from their report highlights the conceptual additional transmission lines required to meet $20 \%$ of generation from wind by 2024.

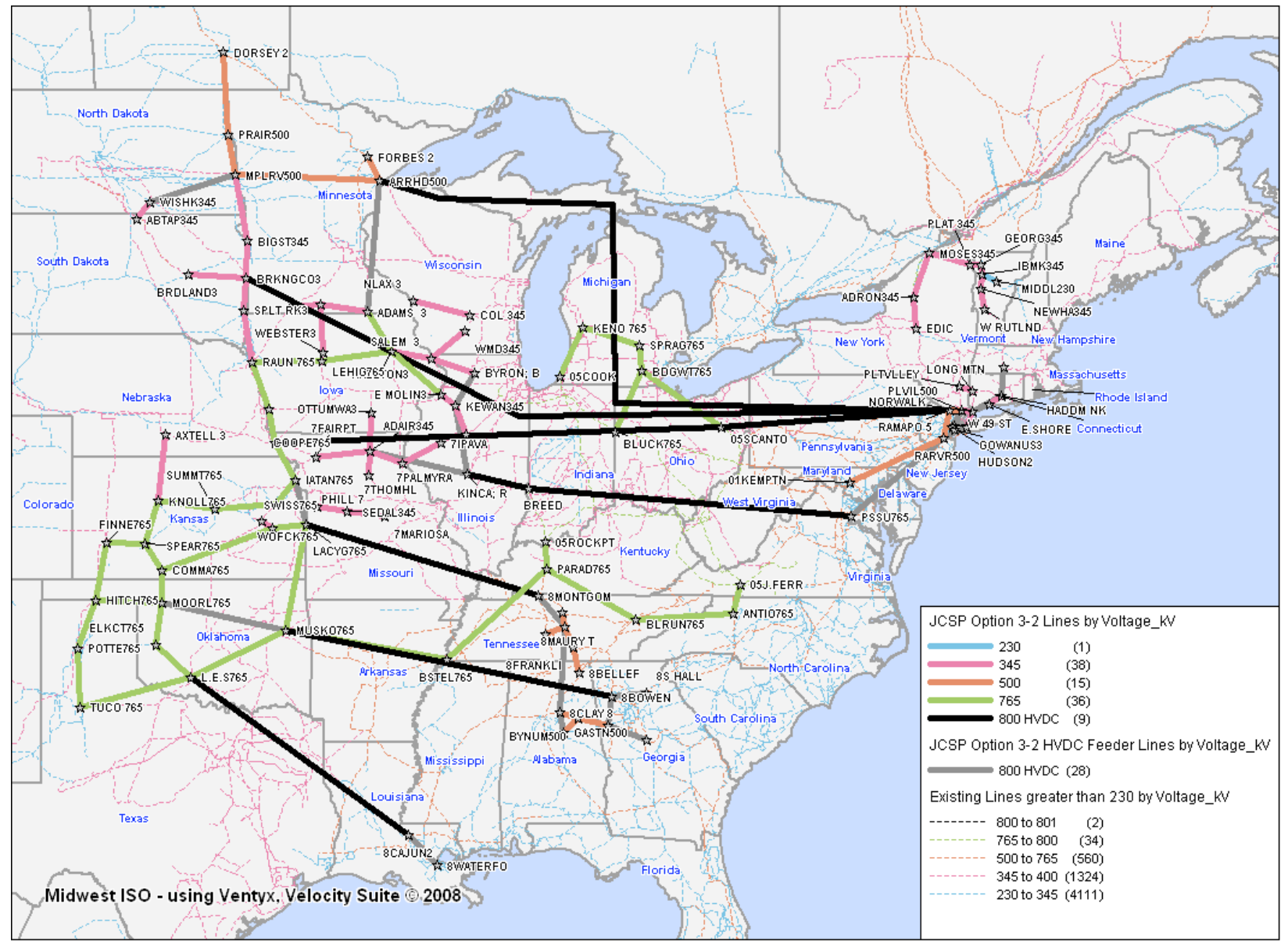

Figure 24. 20\% Wind Energy Scenario Conceptual Transmission Overlay (Source JCSP 2008)

The JCSP scenario shown above was done in support of the DOE Eastern Wind Integration and Transmission Study (EWITS). This study is analyzing five scenarios: Reference; 20\% - High Capacity Factor, On Shore Wind; 20\% - Hybrid with Offshore Wind; 20\% - Local, with Aggressive Offshore; and 30\% - Aggressive On- and Off-Shore. The study is looking at operational impacts and costs from large-scale wind development and the benefits/costs of local 
versus remote wind generation strategies. Aside from TVA, the study is not including the Southeast in its study, although they do consider the regional demands in the analysis (Figure 25). The study is ongoing, with the final report not due until August 2009, but several interesting analyses have already been presented at seminars and workshops. For example, Figure 25 shows the interchange energy flows under Scenario 2, hybrid local and offshore wind generation.

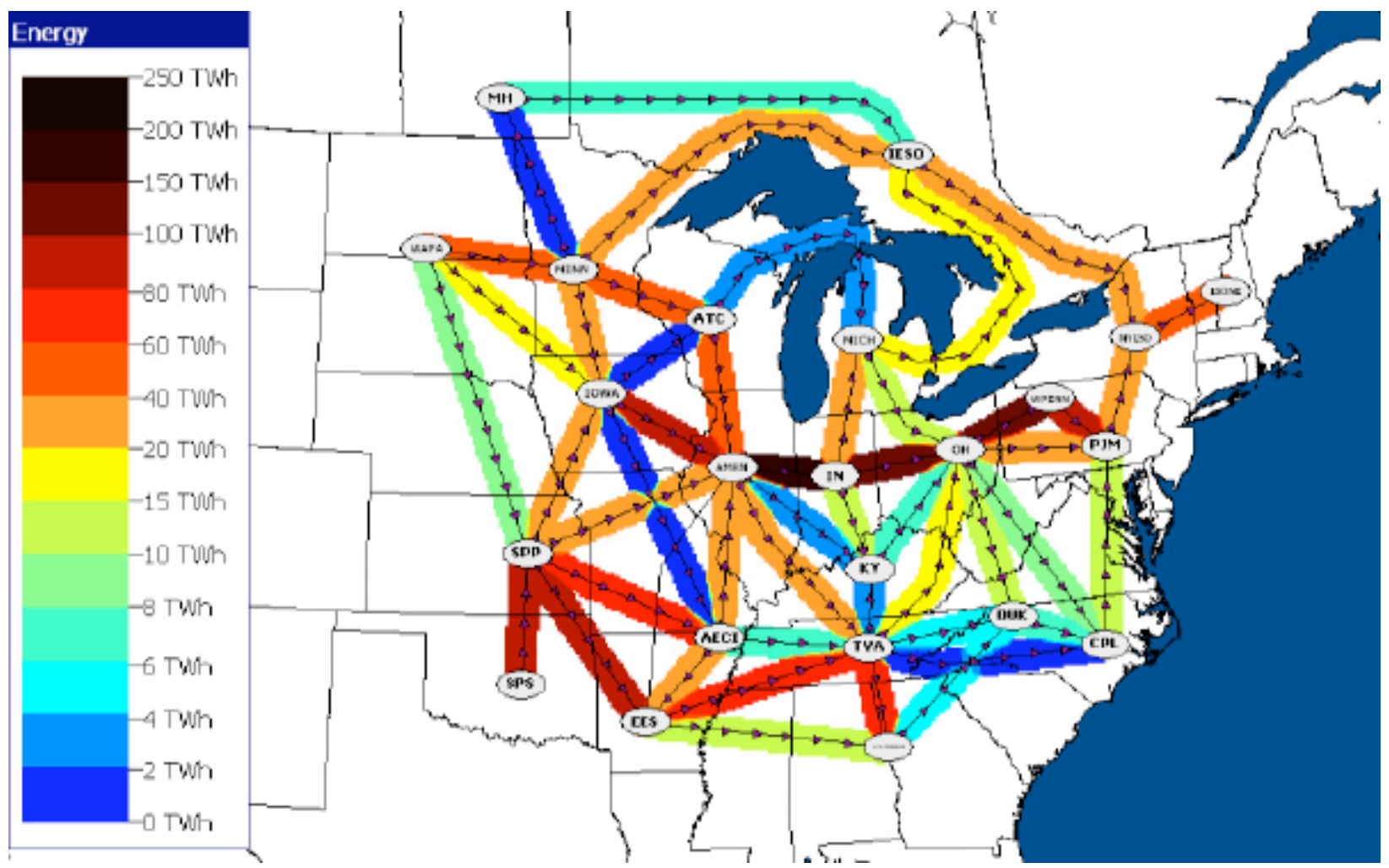

Figure 25. Scenario 2 Interface Contour: Annual Energy Difference Copper Sheet Minus Constrained Case (Source NREL 2009) 
RPS Impacts on the Southeast: Interim Report 2 


\section{Summary}

Policies will have a big effect on the generation mix and the cost of electricity across the country. Some regions would build additional renewable capacity to meet their RPS, even though it may be higher cost than that generated elsewhere. However, with transmission constrained, regions with higher potential low-cost renewable capacity may not fully exploit that capacity and build for export. Similarly regions that do not have renewable resources are not likely to plan for imports.

Deployment of renewable generation is expected to increase significantly because of favorable policies and improvements in technology. This is true in all regions of the US. However, alternatives are limited for the Southeast to generate more than $10 \%$ of electricity consumption from renewable resources. The two main reasons are lack of renewable energy resources and relatively high consumption of electricity. Florida has the biggest challenge in this regard.

A policy for tradable renewable energy credits would provide one alternative for SERC and Florida to make up a shortfall in renewable energy. However this will be limited by the ability of other regions to produce and balance the higher percentage of variable renewable resources. It also represents a fairly large transfer of wealth in the case of the Southeast.

Several studies using different modeling tools (outlined in the sections above) all point to the need to import significant quantities of renewable power into the Southeast. Because of the magnitude involved, this would likely include both the energy and the balancing responsibility. This creates a rather substantial paradigm change in the way different regions plan to meet future demand. These massive imports and exports will also require new transmission infrastructure to enable the transfers. Such a paradigm shift will also require related regulatory changes and expansions of energy markets. 
RPS Impacts on the Southeast: Interim Report 2 


\section{References}

EPRI 2007, Assessment of Waterpower Potential and Development Needs, EPRI 1014762 , March. http://mydocs.epri.com/docs/public/000000000001014762.pdf

EIA 2008, Energy Market and Economic Impacts of S. 2191, the Lieberman-Warner Climate Security Act of 2007, EIA, March.

http://www.eia.doe.gov/oiaf/servicerpt/s2191/index.html

EIA 2009a, Annual Energy Outlook 2009 With Projections to 2030, DOE/EIA-0383(2009), Energy Information Administration, March.

http://www.eia.doe.gov/oiaf/aeo/index.html

EIA 2009b, Impacts of a 25-Percent Renewable Electricity Standard as Proposed in the American Clean Energy and Security Act Discussion Draft, SR/OIAF/2009-04, Energy Information Administration, April.

http://www.eia.doe.gov/oiaf/servicerpt/acesa/index.html

EPRI 2009, Role of Future Generation Options for the U.S. Electric Sector, Report 1015805, Electric Power Research Institute, March.

Milbrandt, A. 2005, A Geographic Perspective on the Current Biomass Resource Availability in the United States, NREL/TP-560-39181, National Renewable Energy Laboratory, December. http://www.nrel.gov/docs/fy06osti/39181.pdf

Paidipati, J., L. Frantzis, H. Sawy;er, and A. Kurrash 2008, Rooftop Photovoltaics Market Penetration Scenarios, NREL/SR-581-42306, National Renewable Energy Laboratory, February.

http://www.nrel.gov/docs/fy08osti/42306.pdf

NREL 2009, Eastern Interconnection Wind Integration \& Transmission Study (Draft), NREL, Midwest ISO, and Enernex, 2009.

http://wind.nrel.gov/public/EWITS/

Navigant 2008, Florida Renewable Energy Potential Assessment, Navigant Consulting, Dec.

SACE 2009, Yes We Can: Southern Solutions for a National Renewable Energy Standard, Southern Alliance for Clean Energy Feb. 2009

Sullivan, Patrick, Jeffrey Logan, Lori Bird, and Walter Short, 2009, Comparative Analysis of Three Proposed Federal Renewable Electricity Standards, NREL/TP-6A2-45877, National Renewable Energy Laboratory, May 


\section{Appendix A The Integrated UPlan Model}

\section{Introduction}

LCG Consulting (LCG) is a widely recognized leader in modeling of competitive electricity and gas markets, for both market design and business planning. We are one of the first companies to research and quantify the implications of competitive pricing and marketing and develop models and database to analyze competitive power markets.

To address various business and regulatory issues in the evolving market environment, LCG has developed models for all aspects of short- and long-term operation and planning in the electric and gas utility industries. LCG has built integrated electricity generation and transmission models for all the ISOs and regions in the United States. Our international experience includes building nodal and zonal grid models for UK (1989), Spain (1991), and Russian (2003)). Currently we are developing an electric power and natural gas system simulator for the Greek Regulatory Authority for Energy (RAE). LCG's path-breaking study for California has set the standard for restructuring analysis throughout the U.S.

LCG's flagship model, UPLAN Network Power Model (UPLAN-NPM), is a full network model developed to replicate the engineering protocols and market procedures of an operator, and captures the commercial activities, such as bidding, trading, hedging, and contracting, of all players in a restructured power market. It projects detailed physical and financial operations of electricity markets conditions ranging from traditional regulation to today's post-restructuring competitive market structures. The model provides the consistent, structured framework, as well as the detailed quantitative inputs and results, required to evaluate the full implications of different fundamental drivers and market participant decisions.

UPLAN is capable of simulating all different types of generators such as thermal, hydro, wind and renewable, cogeneration and many other technologies. An in-line hydro scheduler dispatches hydro, pumped storage and CAES units daily and hourly to maximize net income. UPLAN can represent almost any kind of generation, transmission and a combination of loads. UPLAN unit commitment and dispatch algorithm performs coordinated marginal (opportunity) cost-based energy and ancillary service procurement, AC/DC optimal power flow (OPF), congestion management, full-fledged contingency analysis with Security Constrained Unit Commitment (SCUC) and Security Constrained Economic Dispatch (SCED).

UPLAN-NPM is particularly suitable for optimizing generation and transmission simultaneously. Such an approach is necessary for evaluating renewable technologies such as wind, solar, and storages. Some of the recent renewable energy studies cited below provide examples of UPLAN's unique capabilities. 
$\checkmark$ Cost Benefit and Transmission Analysis: Cost benefit analysis of Texas Competitive Renewable Energy Zones (CREZ) Transmission Optimization Study for Scenarios 1, 2, and 3. Testified before PUCT.

$\checkmark$ Generation/Transmission Analysis: Complete RPS feasibility analysis for 2020 for ORNL/EPRI for Eastern Interconnection to determine the inter-zonal flows using UPLAN.

$\checkmark$ Wind Integration: Large-scale wind development in ERCOT, MISO, PJM, New York and California (Multi-phase analyses for several clients)

$\checkmark$ Transmission and Load Flow Analysis: Transmission investment and load flow analysis for several large wind farms in ERCOT, MISO, and PJM.

$\checkmark$ Solar Power and Battery Integration: Solar study in Mohave and battery feasibility study in California, Washington, ERCOT and PJM.

$\checkmark$ Storage Studies: LCG has undertaken several storage studies to analyze the feasibility of CAES in ECAR (Norton), ERCOT (AE), and several pumped storage plants in California.

$\checkmark$ Coal Performance and Wind Integration: Several studies for global initiative were conducted for EPRI in the last five years.

\section{UPLAN Network Power Model}

UPLAN-NPM simulates the day-ahead energy and ancillary service market using a SecurityConstrained Unit Commitment (SCUC) and Security-Constrained Economic Dispatch (SCED) similar to those used by most market operators in the country. In the first step of the SCUC, the model schedules day-ahead resources in appropriate amounts and locations to meet forecast energy (load) and ancillary service (reserve) requirements, while also taking into account region-specific operating protocols and transmission constraints. The Optimal Power Flow (OPF) simulation is then used to ensure that the final unit commitment can obey all transmission constraints, including line contingencies and generator outages.

The generators are dispatched to meet load in the most economical manner based on generator bids (costs) and subject to transmission constraints. It determines the hourly injection from the output levels of individual generators including renewable. The OPF simulation may utilize either DC or AC power flow, and the system will be optimally redispatched to manage congestion while obeying transmission constraints. The schematics of UPLAN are presented in Figure 1 below. 


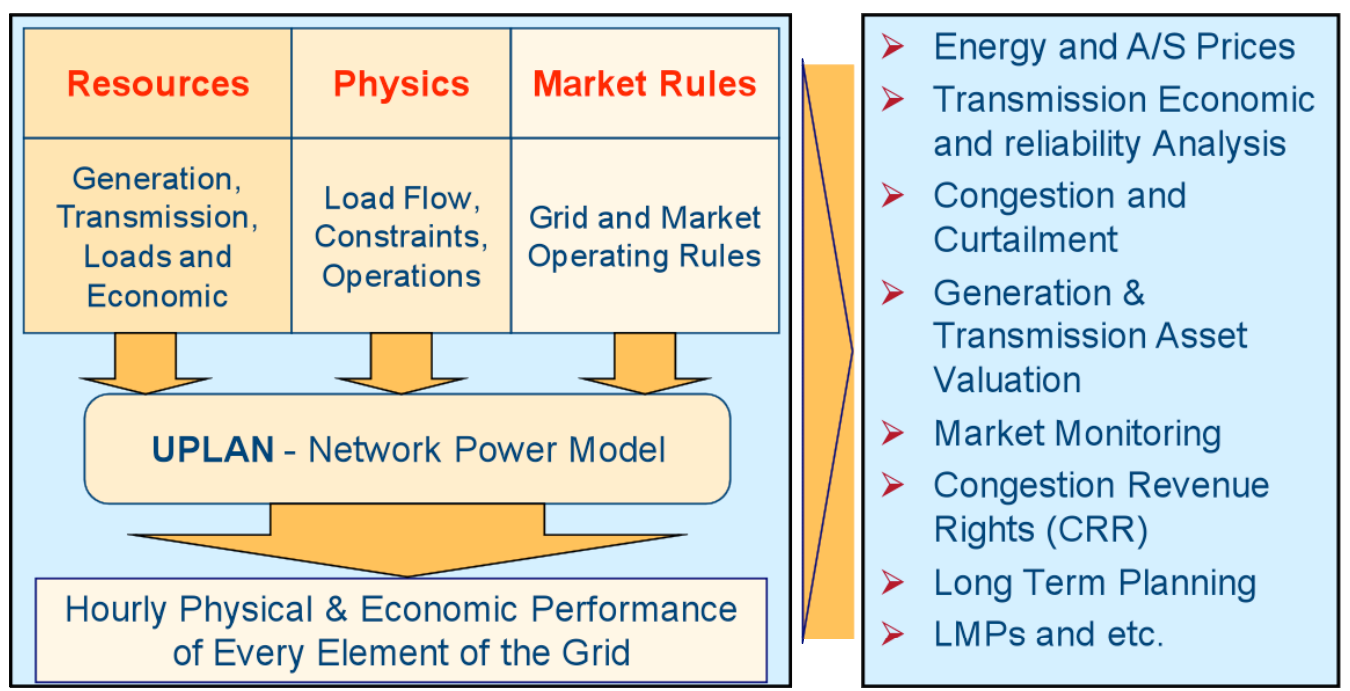

Figure 1. Approach to Market Simulation in UPLAN

\subsection{Modeling Generating Plants in UPLAN}

The LCG Generator Database includes a wide range of generating technologies and variables that are salient to the diverse set of fuel type available, such as coal, gas, wind, hydropower and other renewable resources. A variety of bidding options are available on a unit basis that incorporate block heat rates, minimum up and down times, start-up costs, etc. Bidding behavior can be adjusted over time to reflect monthly load changes, scarcity, and so forth. Figure 2 summarized the generator characteristics modeled in UPLAN. The information for each generating or supply unit is currently stored as a record in the Generator Database as shown in Figure 3 below.

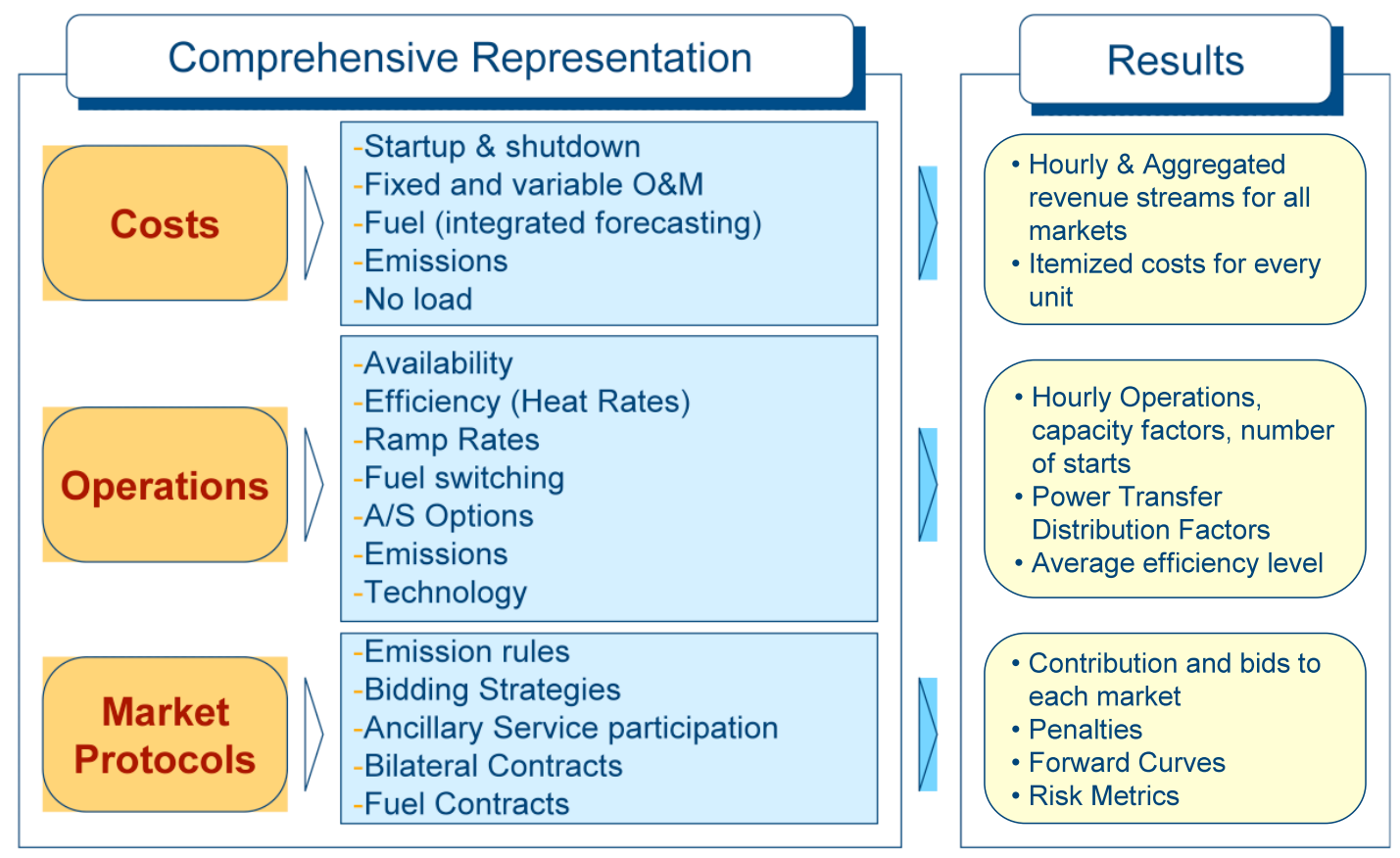

Figure 2. Generator Characteristics Modeled in UPLAN 


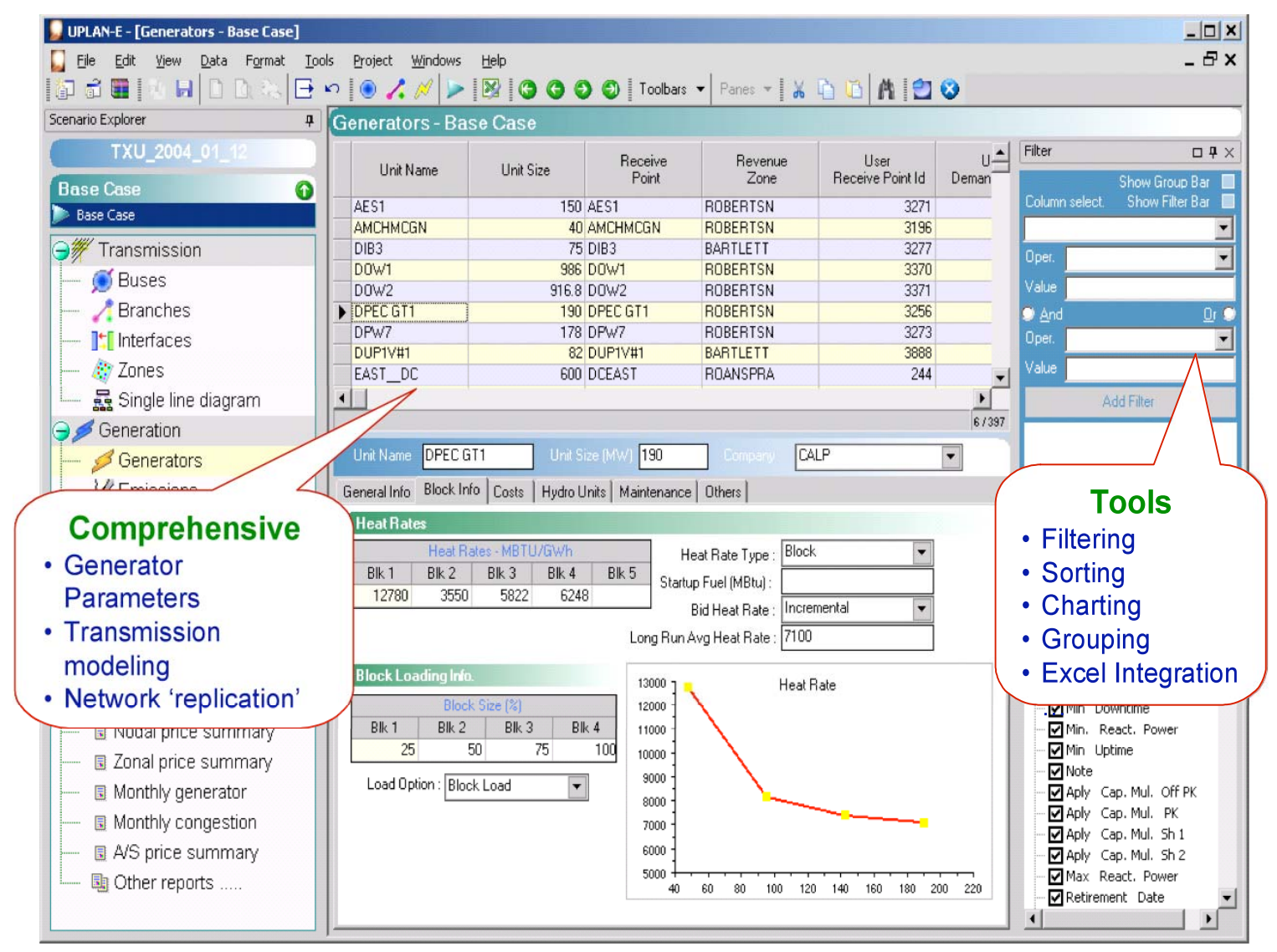

Figure 3. Detailed Presentation of Generating Assets

Each record consists of more than 250 fields of data including all characteristics of each supply unit, identified by a name and unique ID. The major categories of operating characteristics include availability, loading options, fixed, start-up and variable costs, and emissions rates. Fuel costs, fixed costs, and variable costs associated with running the generation units, and financial escalation rates or escalation schedules for these costs, are entered on a monthly basis.

System costs and operating characteristics of both existing and planned capacity are included in this database. General input data include financial escalation rates, unit commitment procedures and emissions categorization. Units may be made candidates for retirement, subject to the criteria set for emissions/new entrant analysis.

\subsection{Modeling Loads in UPLAN}

The UPLAN load module provides a way to create and manipulate load data. This module allows the user to add and remove a demand, manage yearly load profiles, manage monthly and annual load forecasts, display loads graphically (Figure 4). 


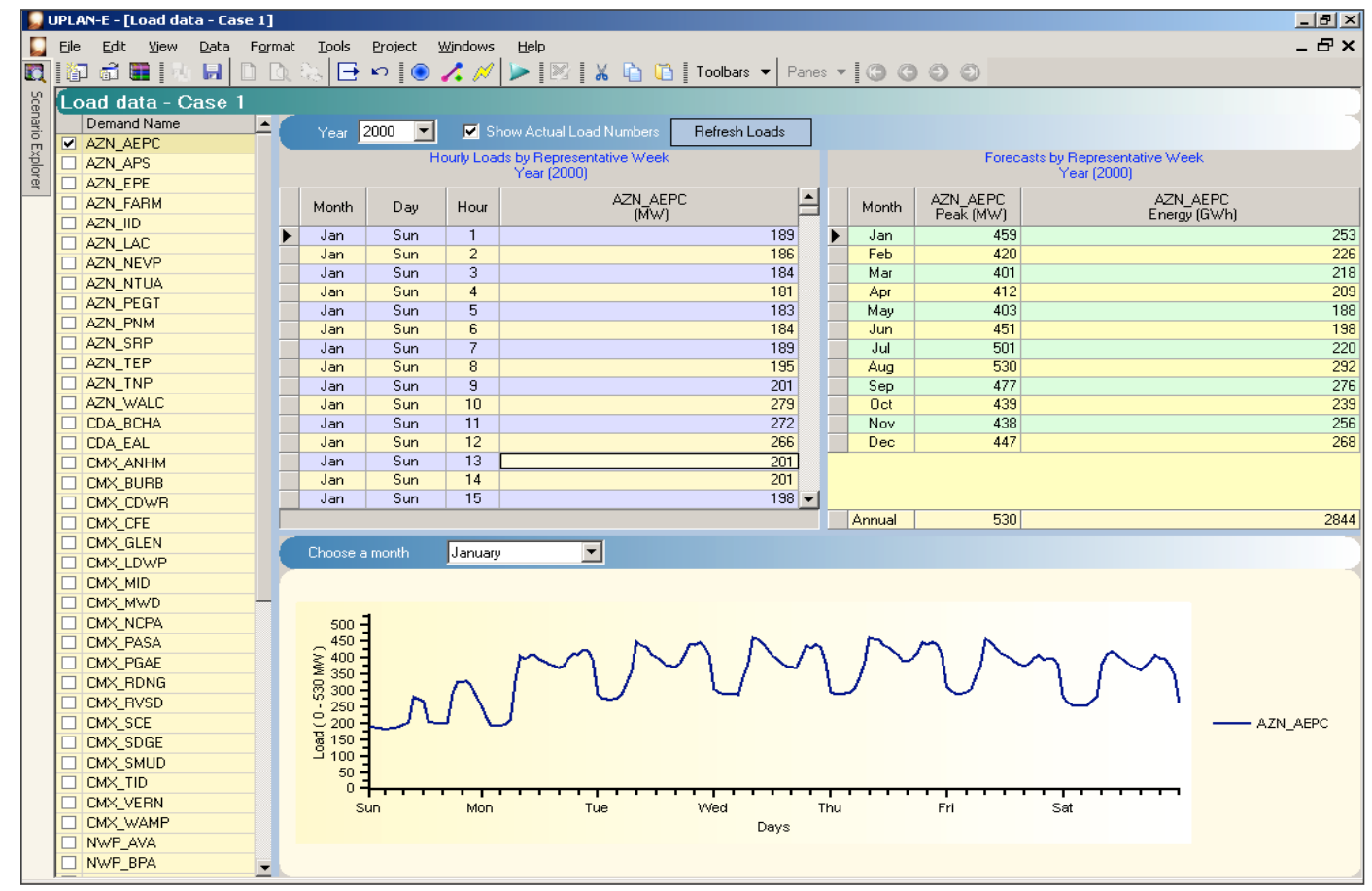

Figure 4. Chronological Hourly and Zonal Load Representation in UPLAN

UPLAN develops peak and energy based on econometric projections for the future years. It offers a variety of ways to determine the hourly load shapes for future years from the peak and energy forecast. The methodology depends on determining the load factor with minimum changes to the hourly profile. In each case the peak MW and total energy demand are used to modify the loads as described below.

a. Static Load scaling - This method assumes that the load profiles are identical from one year to another. The load profile forecast is obtained by adjustment based on peak load forecast or energy demand.

b. Dynamic Load Scaling - This method assumes that the load profiles (from previous years) may be adjusted based on both the peak demand and the total energy. Two standard methods Mean-Bias Method and Valley Bias Method are employed to implement dynamic load modification.

Hourly chronological load at each control area is allocated to each bus according to participation factor.

\subsection{Modeling Transmission}

UPLAN is a full network model and has a sophisticated built-in load flow program which optimizes load flow twice every hour, once during unit commitment again during dispatch. The unique complete representation of transmission network allows the use of a full DC load flow 
for unit commitment and DC or AC dispatch for every hour's simulation. In this respect, UPLAN simulates the actual transmission grid operation and generator dispatch. The graphical display of UPLAN Transmission database is given in Figure 5.

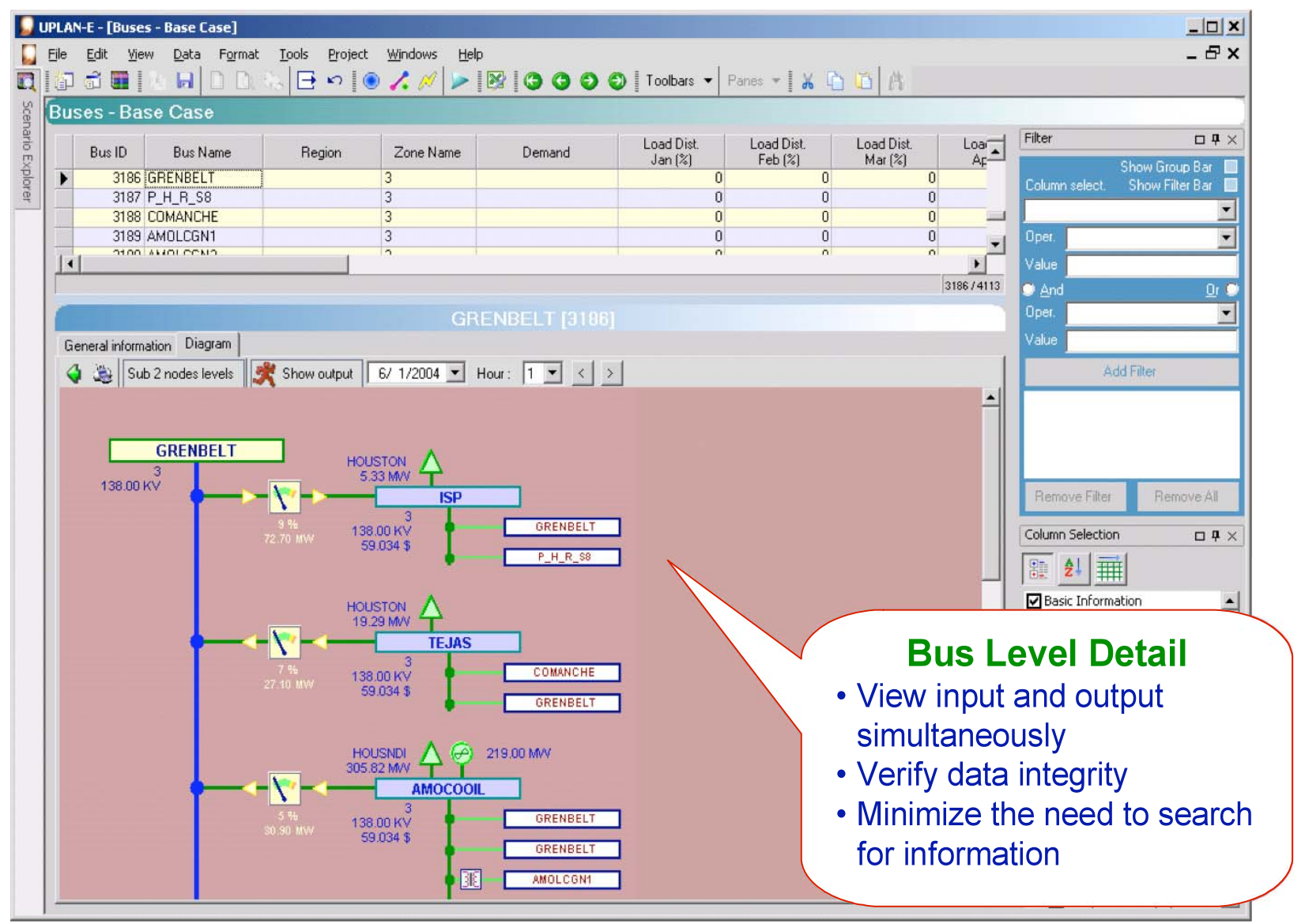

Figure 5. Graphical Display of UPLAN Transmission Database

Other programs generally use a saved load flow program and linear sensitivity factor as replacement for the load flow and as a result unable to model many of the network characteristics shown in Figure 6 below. 
Full Network Representation SCUC and SCED

- Thermal Limits

- N-X Contingency Constraints

- Remedial Action Schemes (RAS)

- Flowgates Nomogram Constraints

- Marginal \& Average Losses

- Phase Angle Regulators (PARs)

- Bus level demand for Energy and A/S
Shadow prices and FTRs

Line Outage

Distribution Factor

(LODF)

Power Transfer Distribution Factor

(PTDF)

Outage Transfer

Distribution Factor

(OTDF)

Figure 6. Transmission Network Characteristics Modeled in UPLAN

\subsection{Ancillary Services Modeling}

UPLAN simulations also reflect co-optimization of energy and ancillary service markets. To determine the economically optimal unit commitment, UPLAN realistically characterizes marginal opportunity cost-based bidding reflecting arbitrage across the different energy and ancillary service markets. Thus, a generator's availability and willingness to sell various ancillary services depends on the resulting reduction of energy sales opportunities, and vice versa. Different A/S products (e.g., regulation, spin, non-spin, 30-minute, and reliability must-run) are integrated into UPLAN day-ahead market simulation. The ability of each generator to participate in each of the $\mathrm{A} / \mathrm{S}$ market is specified in the generator input data. 


\section{UPLAN Day -Ahead Market Simulation Energy \& Ancillary Service Price Forecast}

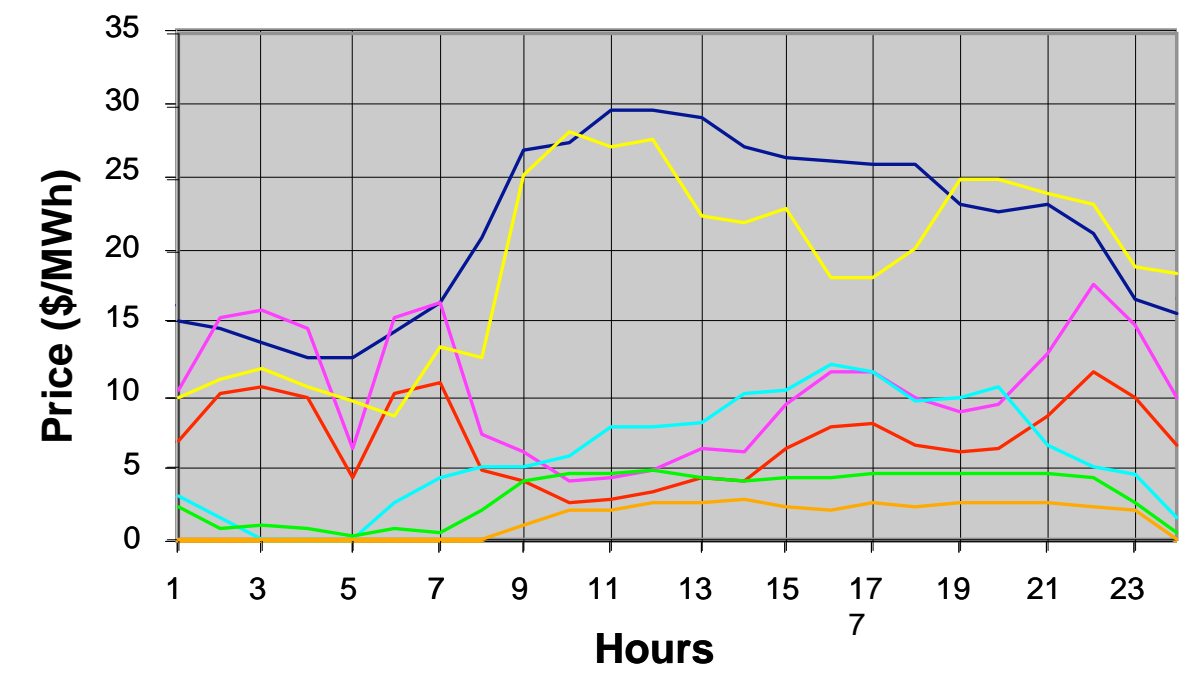

\begin{tabular}{|c|}
\hline Day-Ahead Energy \\
$(\$ / M W h)$ \\
Regulation Up \\
(\$/MW) \\
Regulation Down \\
(\$/MW) \\
Spinning Reserve \\
(\$/MW) \\
Non-Spinning \\
Reserve (\$/MW) \\
Replacement \\
(\$/MW)e \\
Real-time Energy \\
$(\$ / M W h)$ \\
\hline
\end{tabular}

Figure 7. Energy and A/S Price Forecast in UPLAN

\subsection{Volatility Model - Risk Analysis}

The UPLAN Volatility Model enables the uncertainty of underlying fundamental drivers, such as load and fuel prices, to be effectively incorporated in developing forecast expected system operations and electricity prices. The real-time imbalance market is simulated by utilizing a Monte Carlo simulation of the demand, outages, and transmission derating, as well as other short-term volatilities.

For long-term simulation, the model can be used - along with long-term uncertainties of the fundamental drivers - to assess risks associated with any long-term generation or transmission investments and contracts. The model also produces probability distributions and expected values for LMPs, as well as net income distributions for generators, contracts, and the entire portfolio. 


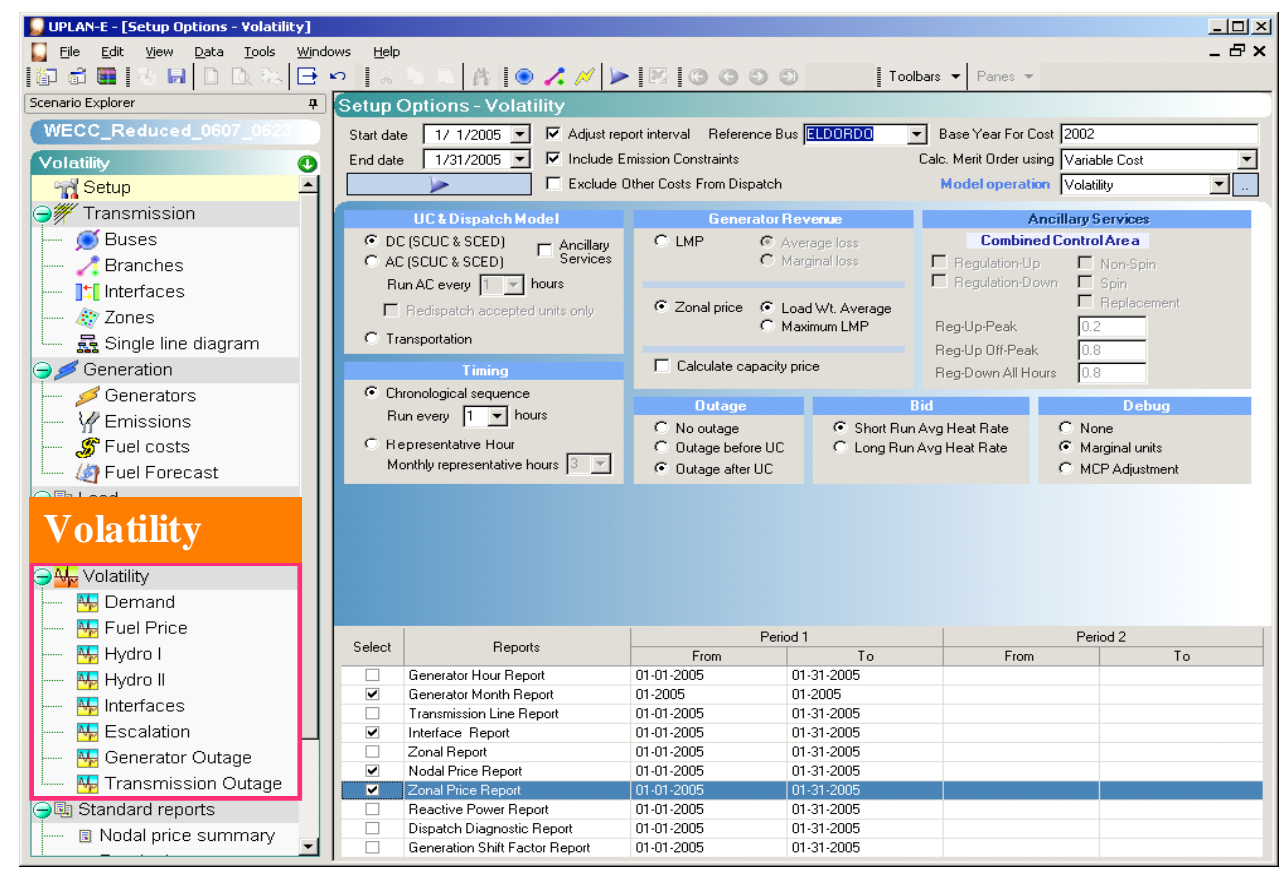

Figure 8. UPLAN Volatility Model

3. UPLAN Outputs and Applications

UPLAN provides a rich repertoire of output reports for electricity prices, generation and transmission in Excel format. A few of the reports are mentioned below.

\section{Electricity Prices}

$\checkmark$ Hourly Locational Marginal Prices at each designated bus

$\checkmark$ Zonal electricity and ancillary service prices

$\checkmark$ Summarized peak, off-peak and monthly average prices for the duration of the simulation

$\checkmark$ Price distribution for LMPs and zonal prices (output from Volatility Model)

$\checkmark$ Call and put prices at designated strike prices

$\checkmark$ Several other reports

\section{Generation}

$\checkmark$ Electricity generation of each unit

$\checkmark$ Production cost of each generator

$\checkmark$ Gross and net revenues of each generating plant

$\checkmark$ Marginal energy and capacity cost (LRMC)

$\checkmark$ Size, timing, and technology of new capacity additions for each market area

$\checkmark$ Annual capital expenditure for each new and existing plant

$\checkmark$ Retirement of the existing units 
$\checkmark \quad$ Life extension of the existing units

$\underline{\text { Transmission }}$

$\checkmark$ Line flow

$\checkmark$ Zonal congestion

$\checkmark$ Total transmission capacity (TTC)

$\checkmark$ Available transmission capacity (ATC)

$\checkmark$ Binding contingency

$\checkmark$ Voltage Violation/Capacitor Dispatch

\section{$\underline{\text { Financials }}$}
$\checkmark$ Costs and revenues of each resources
$\checkmark$ Performance of bilateral contracts
$\checkmark$ Congestion revenues and CRRs
$\checkmark$ Transmission and congestion contracts (TCCS)
$\checkmark$ Zonal flows and revenues
$\checkmark$ Energy and ancillary services prices and call/put option values
$\checkmark$ Generator revenues, net income and call/put option values at various strike prices
$\checkmark$ Gamma, Delta, Theta and other Greeks
$\checkmark$ Value at Risks, value of call/put premiums for all resources including CRRs

In Sum, UPLAN offers the following functional capabilities:

- Day-Ahead Security Constrained Unit Commitment process and Security Constrained Economic Dispatch

- Congestion management in day-ahead and during dispatch

- Use of transmission constraints and resolve all congestion in the day-ahead markets

- Distributed marginal (or average) losses for unit commitment and dispatch

- Co-optimization of energy and ancillary services

- LMPs for energy at every node and A/S prices at every ISO controlled Zone

- Zonal as well as Nodal modeling

- Volatility analysis for generator and transmission valuation as well as capacity expansion

\section{A Common Database for Generator, Transmission, and Customer Load}

UPLAN-NPM operates in an efficient and powerful MS SQL Server environment using the latest technologies to rapidly view, manipulate and manage the large, complex data sets necessary for realistic market simulation and analysis. It is conveniently addressed via "scenario" based storage, freeing the user from many laborious data management tasks and minimizing the risk 
of overwriting or accidentally deleting data. UPLAN-NPM offers an integrated environment to view or modify all input data, with both standard and customized reporting. Its intuitive interfaces contain countless time saving features, including sorting, grouping, filtering, data validation, seamless Excel integration and custom charting, see Figure 9.

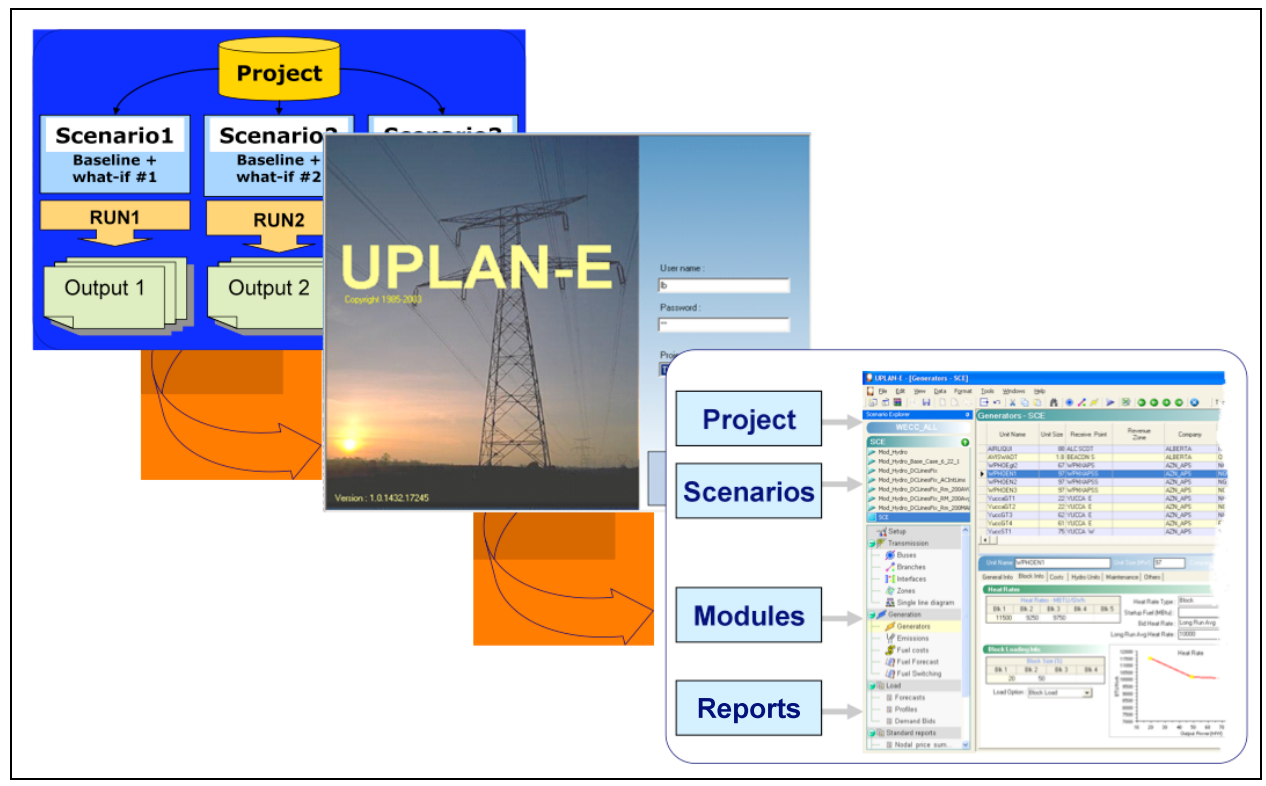

Figure 9. UPLAN User Interface Database Structure

The UPLAN database is organized as a relational database with a global store for all the input information. It is further organized in projects and scenarios for ease of use, management, and security. Since it is a standard RDBMS system, there is transparency and flexibility as to the data. Tasks, such as incorporating external data or exporting UPLAN data to XML, are easily accomplished. Furthermore, no distinction is made between input and output so that users can seamlessly make excursion to input and output database to create new reports, perform economic input and output analysis, and store results for future use.

The integrated UPLAN models and database provide a solid foundation for modeling, database management and performing all planning functions. 